\title{
WestVirginiaUniversity
}

THE RESEARCH REPOSITORY @ WVU

Graduate Theses, Dissertations, and Problem Reports

2017

\section{Parental Socialization of Child Gratitude and Links to Child Outcomes}

Boglarka K. Vizy

Follow this and additional works at: https://researchrepository.wvu.edu/etd

\section{Recommended Citation}

Vizy, Boglarka K., "Parental Socialization of Child Gratitude and Links to Child Outcomes" (2017). Graduate Theses, Dissertations, and Problem Reports. 6877.

https://researchrepository.wvu.edu/etd/6877

This Thesis is protected by copyright and/or related rights. It has been brought to you by the The Research Repository @ WVU with permission from the rights-holder(s). You are free to use this Thesis in any way that is permitted by the copyright and related rights legislation that applies to your use. For other uses you must obtain permission from the rights-holder(s) directly, unless additional rights are indicated by a Creative Commons license in the record and/ or on the work itself. This Thesis has been accepted for inclusion in WVU Graduate Theses, Dissertations, and Problem Reports collection by an authorized administrator of The Research Repository @ WVU. For more information, please contact researchrepository@mail.wvu.edu. 
Parental Socialization of Child Gratitude and Links to Child Outcomes

Boglarka K. Vizy, M.A.

Thesis submitted to the Eberly College of Arts and Sciences at West Virginia University in partial fulfillment of the requirements

for the degree of

\author{
Master of Science \\ in \\ Psychology
}

\author{
Amy Gentzler, Ph.D. Chair \\ Aaron Metzger, Ph.D. \\ Amy Root, Ph.D.
}

Department of Psychology

Morgantown, West Virginia 2018

Keywords: children, gratitude socialization, depression, well-being, social skills Copyright 2018 Boglarka K. Vizy 


\section{ABSTRACT \\ Parental Socialization of Child Gratitude and Links to Child Outcomes}

\section{Boglarka K. Vizy}

Research shows that the gratitude is associated with positive mental health in both adults and children. However, research on how gratitude is learned or socialized is limited. The goal of the proposed study was to examine parental socialization of gratitude and its relation to children's gratitude to predict children's positive affect, depressive symptoms, and social skills. A mediation model was tested to determine if children's gratitude explained the link between mother socialization and child outcomes. It was expected that these indirect paths would be stronger for older children. Participants were 95 mother-child dyads who completed a battery of questionnaires and a video-recorded discussion task that was coded for socialization and understanding of gratitude. Using Hayes' PROCESS, a moderated mediation model indicated that mother's elaboration of gratitude during the discussion task was associated with higher levels of communication skills for children through children's understanding of gratitude, with the path from children's gratitude understanding to communication being moderated by child age. In other words, mothers' socialization of gratitude led to a better understanding of gratitude for children, which then led to increased communication skills for older children specifically. These results are important because they provide evidence for the paths through which gratitude is socialized in children. As a result, this study may prompt further research and the development of gratitude interventions to increase gratitude understanding in children and ultimately, the overall well-being and social skills of individuals.

Keywords: children, gratitude socialization, depression, well-being, social skills 


\section{TABLE OF CONTENTS}

I. Abstract (pp. ii)

II. Introduction (pp. 1-14)

III. Method (pp. 14-22)
a. Participants (pp. 14-15)
b. Procedure (pp. 15)
c. Measures (pp. 15-22)

IV. Results (pp. 23-32)
a. Preliminary analyses (pp. 23-27)
b. Primary analyses (pp. 27-32)

V. Discussion (pp. 32-52)

VI. References (pp. 53-65)

VII. Table 1: Descriptive Statistics for Mom and Child Demographic Information (pp. 66)

VIII. Table 2: Coding Scheme for Mothers’ and Children’s Gratitude Definitions and Examples (pp. 67)

IX. Table 3: Mothers’ and Children’s Gratitude Examples (pp. 68)

X. Table 4: Correlations Between Key Study Variables and Participant Socio-Demographic variables (pp. 69)

XI. Table 5: Correlations between Mediator Variables (Children’s Gratitude) and Child Outcomes (pp. 70)

XII. Table 6: Correlations between IVs (Mom Socialization; pp. 71)

XIII. Table 7: Correlations between Mediators (Children’s Gratitude; pp. 72)

XIV. Table 8: Correlations between Child Outcome Variables (pp. 73) 
XV. Table 9: Correlations between IVs (Mom Socialization) and Mediators (Children's Gratitude; pp. 74)

XVI. Table 10: Correlations between Mediator Variables (Children’s Gratitude) and Child Outcomes (pp. 75)

XVII. Table 11: Correlations between IVs (Mom Socialization) and Child Outcomes (pp. 76)

XVIII. Table 12: Regression Analyses Examining Mom Socialization Variables Predicting Children’s Gratitude (Mediator Variables) using Standardized Betas (pp. 77)

XIX. Table 13: Regression Analyses Examining Children’s Gratitude Predicting Child Outcomes using Standardized Betas (pp. 78)

XX. Figure 1: Testing the hypothesis that mom's elaboration of gratitude is associated with child communication skills through children's gratitude (presented via standardized beta values; pp. 79)

XXI. Appendices (pp. 80-90)

a. Appendix A: Mothers' Socialization of Gratitude \& Children’s Gratitude (pp. 81-87)

b. Appendix B: Children’s Outcome Measures (pp. 88-90) 
Parental Socialization of Child Gratitude and Links to Child Outcomes

Gratitude has been consistently linked to a multitude of benefits for individuals such as higher well-being, greater positive social interactions, and lower depressive symptoms (Algoe, Fredrickson, \& Gable; 2013; Algoe, Haidt, \& Gable, 2008; Emmons \& Mishra, 2012; Froh, Bono, \& Emmons, 2010; Froh, Miller, \& Snyder, 2007; Kong, Ding, \& Zhao, 2015; Wang, Wang, \& Tudge, 2015; Wood, Joseph, \& Maltby; 2008a). Research on gratitude illuminates the reasons why people should engage in grateful acts, but there is limited research on the cultivation of gratitude. Because research addressing socialization of both positive and negative emotions with children is plentiful (Chaplin, Cole, \& Zahn-Waxler, 2005; Denham, Workman, Cole, Weissbrod, Kendziora, \& Zahn-Waxler, 2000; Fredrickson, 1998; Klimes-Dougan, Brand, ZahnWaxler, Usher, Hastings, Kendziora, Garside, 2007; Morris, Silk, Steinberg, Myers, \& Robinson, 2007; \& Yap, Allen, \& Ladouceur, 2008), this study draws from this large literature to understand socialization of gratitude specifically. Furthermore, research shows that gratitude is not present in infants, but may develop as children gain social cognitive abilities and enhanced through the socialization process carried out by parents, similiar to the socialization of emotions as their children grow (Wang, Wang, \& Tudge, 2015).

Developmental research on positive emotions indicated that feelings of appreciation and thinking positively may develop as early as five years of age (Bamford \& Lagattuta, 2012). However, due to the complex nature of gratitude, most gratitude researchers postulate that understanding gratitude to its full extent does not emerge until around seven years of age and continues to increase into adolescence (Froh, Kashdan, Ozimkowski, \& Miller, 2009a; Layous \& Lyubomirsky; 2014). For example, in a study assessing gratitude understanding in elementary students, researchers measured gratitude ratings based on vignettes describing desirable versus 
undesirable gifts. Results showed that older children (fourth and fifth graders, about 9-11 years) had higher ratings of gratitude for desirable gifts, but also for undesirable gifts (Poelker \& Kuebli, 2014). This suggests that older children understand gratitude in a different way than younger children do (first and second graders, about 6-8 years of age). Perhaps older children take into account more than just the likability of a gift, and understand the effort made by the benefactor as compared to first and second graders (Poelker \& Kuebli, 2014). Gratitude expression has implications for the overall psychological adjustment of children (Froh et al., 2010; Froh, Emmons, Card, Bono, \& Wilson, 2011a; Froh, Fan, Emmons, Bono, Huebner, \& Watkins, 2011b; Tian, Hu, \& Huebner, 2014) and as a result, it is important to continue research on parental socialization of gratitude.

The current study will explore the association between parental socialization of children’s gratitude and child outcomes, while assessing the role of children's gratitude as a mechanism through which this process takes place. Furthermore, age will be examined as a moderator with the hypothesis that the mediation model will be stronger for older adolescents. Specifically, the path from parental socialization of gratitude to children's gratitude and subsequently the path from children's gratitude to child outcomes are both expected to be moderated by age. Thus, this study can provide evidence for the developmental trajectory of gratitude and support for the hypothesis that the understanding and expression of gratitude, especially for older adolescents is the mechanism through which parental socialization of gratitude may lead to higher levels of well-being, increased social skills, and lower levels of depressive symptoms.

\section{Gratitude and its Potential Benefits}

There are numerous conceptualizations of gratitude in the emotion literature. Many definitions of gratitude have been used, ranging from descriptions of gratitude as an emotion, 
affective trait, virtue, and even a character strength (Emmons \& McCullough, 2004). Perhaps one of the first definitions of gratitude comes from Kant in the late 1700's as he states that gratitude means "honoring a person because of a kindness he has done on us.” (p. 5; Emmons \& McCullough, 2004). Other definitions of gratitude include "an estimate of gain coupled with the judgment that someone else is responsible for that gain" and as an emotion "it is important that gratitude has a positive valence: it feels good” (p. 5; Solomon, 1977 in Emmons \& McCullough, 2004).

Gratitude has also been conceptualized both as a state phenomenon, as well as a dispositional characteristic or trait phenomenon (Roberts, 2004). As a trait, an individual practices gratitude as part of their daily life (McCullough, Emmons, \& Tsang, 2002), whereas the emotional reaction to another individual's expression of gratitude is referred to as state (Watkins, Van Gelder, \& Frias, 2009). Gratitude as an affective trait refers to a predisposition towards certain types of emotional states. People who score highly on measures of gratitude as a dispositional trait tend to experience higher levels of positive effects such as happiness, vitality and hope and low levels of negative effects such as resentment, depression and envy (Emmons \& McCullough, 2003). In line with gratitude as an enduring trait, some psychologists believe that the moral aspect of gratitude represents gratitude as a virtue that a human being needs to flourish or to live well (Froh et al., 2007). This is similar to the conceptualization of gratitude as a character strength, which can be promoted and developed through the practice or cultivation of gratitude over time (Park, Peterson, \& Seligman, 2004).

Currently, gratitude is most often discussed as an emotion, most researchers agree that gratitude is a more complex and higher-level emotion because it requires an advanced level of cognitive input than other positive emotions such as happiness and joy (Emmons \& McCullough 
2003). Furthermore, gratitude is also described as a social emotion due to the social exchange that occurs between a benefactor and beneficiary (Emmons \& McCullough, 2003). In essence, gratitude is a relationship-strengthening emotion that involves both thought and action (Emmons \& McCullough, 2004). The action tendencies associated with gratitude include both verbal and physical displays of gratitude, despite the fact that gratitude displays no regular or recognizable facial expression (Emmons \& McCullough, 2004). Additionally, the emotional aspect of gratitude is extended to also encompass a learning environment (e.g., social situation, reciprocity) for social skills (Emmons \& McCullough, 2004).

For the purposes of this study, the following definition is used to convey the meaning of gratitude. According to Emmons and McCullough (2003), "gratitude is an emotion that results from realizing that one has obtained a positive outcome and that this outcome can be attributed to an external source" (p. 378). Additionally, Robert Solomon stated that "being capable of and expressing gratitude ... is not just an acknowledgment of debt and an expression of humility but is also a way to improve one's life. One can take one's life and its advantages for granted, but how much better it is to acknowledge not only these advantages but one’s gratitude for them.” (p. vii; Emmons \& McCullough, 2004). Feelings of gratitude surface when people realize that a benefactor has expended energy to benefit them (Bird \& Markle, 2012; Emmons \& McCullough, 2003). In other words, gratitude represents feelings of appreciation that develop as a result of receiving gifts and benefits from others, but at the same time motivating individuals to pay it forward, and to share these gifts and benefits with those around them (Algoe et al., 2008; Froh et al., 2011b). Of key importance within this definition is the focus on the social exchange that occurs between the beneficiary and the benefactor. Furthermore, this definition is relevant because it highlights the importance of gratitude expression through the achievement of a 
positive outcome and the increase of positive emotions as a result. Consequently, individuals who practice gratitude are better able to understand the perspective of others and therefore, are more likely to continue the social exchange process by helping other individuals (Froh et al., 2009b). Because gratitude is a complex emotion that may be more difficult to understand than basic emotions (Emmons \& McCullough 2003), it is important to study the socialization of gratitude specifically to contribute to existing research on socialization of positive and negative emotions in general.

Until recently, not much research has focused on gratitude within the field of psychology, especially with children. However, numerous research studies show the relation between gratitude and well-being for children and adolescents (Emmons \& McCullough 2003; Froh et al., 2009b; McCullough, Emmons, \& Tsang, 2002; McCullough, Tsang, \& Emmons, 2004; Tian et al., 2014; Wood, Froh, \& Geraghty, 2010). It is posited that as people learn to be more appreciative of the world (Wood et al., 2010) they learn to build up their strengths, like gratitude, to increase well-being (Seligman \& Csikszentmihalyi, 2000; Wood et al., 2010). Moreover, longitudinal studies show that certain character strengths of individuals, like gratitude, are potential predictors of global life satisfaction (Froh, Bono, Fan, Emmons, Henderson, Harris, Leggio \& Wood, 2014; Froh, Sefick, \& Emmons, 2008; Ruch, Weber, Park, \& Peterson, 2014; Wood, Maltby, Gillett, Linley, \& Joseph, 2008b). Additionally, research shows that emphasizing gratitude during youth development has implications for children’s contribution to their community and society as a whole (Froh et al., 2010). For the current study, we focus on benefits of gratitude that center around the concepts of mental health (well-being and depressive symptoms), and social skills. 
Regarding mental health, higher levels of gratitude in children is associated with fewer depressive symptoms (Froh et al., 2010; Froh, et al., 2011b; Wood et al., 2008b). In one particular study, researchers explored the relation between gratitude and depressive symptoms in undergraduate students and found that higher gratitude at Time 1 was associated with a decrease in depressive symptoms at Time 2, when controlling for baseline depressive symptoms (Lambert, Fincham, \& Stillman, 2012). Additionally, children who report expressing higher levels of gratitude also report improved grades, an overall positive school experience, and lower levels of depression (Froh et al., 2011; Wang et al., 2011). Depressive disorders are characterized by a decrease in positive affect and a surplus of negative affect (Gross \& Levenson, 1997), so increasing gratitude expression may help reverse these emotion levels. Furthermore, the association between gratitude and depressive symptoms was mediated by both positive framing, a skill used to frame negative events in a better light, and by positive emotions, in line with Fredrickson’s (2001) broaden-and-build theory (Lambert et al., 2012). Specifically, broaden and build theory postulates that positive emotions increase or "broaden” one's thoughts and behaviors. Over time, this broadened mindset leads to a variety of skills and resources for that individual (Fredrickson, 2001). For example, experiencing gratitude may promote increased social bonds and creative ways of expressing gratitude, which in turn facilitate social resources (e.g., increased pro-social behaviors) and psychological resources (e.g., coping skills and optimism) vital for optimal health and well-being. According to psychologists, a key component of happiness is said to be gratitude (Emmons \& McCullough 2003; Froh \& Bono, 2008). Higher levels of gratitude help enable individuals to increase their ability to savor positive events (Sheldon \& Lyubomirsky, 2006) and block the expression of negative affect (McCullough et al., 
2002). Furthermore, higher levels of dispositional gratitude are linked to greater self-esteem and indicators of well-being in undergraduate participants (Kong et al., 2014).

Regarding social skills, gratitude is highly appreciated for its ability to support and uplift a multitude of social relationships (Algoe, 2012; Algoe et al., 2008; Algoe et al., 2013; Bartlett \& DeSteno, 2006; Grant \& Gino, 2010; Tian et al., 2014). For example, in a study assessing benefits related to adolescent gratitude experience and expression, participants (ages 11-13) who were more grateful provided more emotional support to others and experienced higher levels of positive affect and social support from individuals in their support system (Froh, Yurkewicz, \& Kashdan, 2009b). In fact, their satisfaction within the domains of family, school, and peers were significantly higher than participants who reported lower grateful moods (Froh et al., 2009b). Additionally, individuals who practice gratitude have an increased sense of self-efficacy and self-worth, which motivates them to engage in prosocial behavior (Grant \& Gino, 2010). Furthermore, gratitude is associated with increased communication and social skills for children and adults (Eisenberg, Fabes, Shepard, Guthrie, Murphy, \& Reiser, 1999; Emmons \& McCullough 2004; Wang et al., 2015). Specifically, in a study assessing expressions of gratitude in Chinese and American cultures, findings indicated that American children (ages 7 to 14) who expressed higher levels of gratitude reported higher levels of well-being and increased social relationships (Wang et al., 2015). This finding is particularly important because the associations between gratitude expression, well-being, and social relationships were stronger for older adolescents, regardless of society, providing support for the theory that gratitude understanding develops over time. Moreover, expression of gratitude may be useful for children and adolescence with peer issues to form closer bonds with others (Froh et al., 2007). As a result, children are liked more by their peers and can engage in positive social behaviors more often 
(Froh et al., 2007). In general, these findings are consistent with the importance of social exchange between a beneficiary and benefactor and it is through this practice of communication/action that children may learn to enhance their social skills and engage in more acts of gratitude (Emmons and McCullough, 2003).

\section{Parental Socialization of Emotions and Child Outcomes}

There is an abundance of research that shows parents play a very crucial role in the socialization of both positive and negative emotions with their children (Chaplin et al., 2005; Denham, 1998; Eisenberg et al., 1998; Fredrickson, 1998; Gentzler et al., 2015; Morris et al. 2007; Zahn-Waxler, 2010). Specifically, parent’s frequent validation and attention to their children's emotions is an essential precursor to mental health (Gottman, Katz, \& Hooven, 1996). However, most of the research focuses on the socialization of negative emotions such as anger, fear, and anxiety in order to examine adverse outcomes (Eisenberg et al., 1999; Fabes, Poulin, Eisenberg, \& Madden-Derdich, 2002; Jones, Eisenberg, Fabes, \& MacKinnon, 2002; McElwain, Halberstadt, \& Volling, 2007). Investigating the socialization of positive emotions is also very important as we see this similar trend with invalidation and dampening of children's positive affect (Fredrickson, 1998; Yap et al. 2008). Ineffective emotion socialization may result in the use of maladaptive strategies and higher levels of externalizing behaviors or internalizing problems (Katz \& Hunter, 2007). Therefore, it is clear that effective emotion socialization is key because there are significant implications for youth mental health.

Parents use a variety of methods when socializing their children’s emotions. From research on positive and negative emotion socialization, it is found that parents often use a simple technique of emotion discussion, where they actively participate with the child in conversing about specific emotions (Eisenberg et al., 1998). They educate the child about what 
emotions mean, how to respond to such feelings, and utilize validation and elaboration methods (Eisenberg et al., 1998). Additionally, parents engage in recurrent emotional talk to explain the antecedents and consequences of emotions that children and adolescents feel (Baker, Fenning \& Crnic, 2010). Some mothers help savor their children's positive emotions and provide emotional support (for both positive and negative emotions) whereas others do not discuss or may have maladaptive discussions where they invalidate or minimize children's emotions (Eisenberg et al., 1998; Fabes et al., 2002; Jones et al., 2002). In general, parents’ engagement in open and validating discussion of children's emotions is crucial because a lack of emotional support for children may result in the failure to learn appropriate skills to sustain and strengthen positive affect (Gottman et al., 1996; Gross \& Muñoz, 1995).

Another common method of emotion socialization is observational learning, or otherwise referred to as modeling (Bandura, 1977; Morris et al., 2007). According to the modeling hypothesis, parents implicitly teach their children appropriate displays of emotion and ways to manage and regulate these emotions (Morris et al., 2007). Although modeling is a popular method of emotion socialization, it also has the potential to teach children ineffective ways to regulate emotion. For example, if parents are displaying erratic and intense negative emotions, children will learn to model these behaviors and are less likely to learn how to regulate emotions effectively in general (Eisenberg et al., 1998; Gottman et al., 1996; Morris et al., 2007). As children grow they frequently experience unfamiliar situations and look to a source of trust (i.e., their parents) for guidance regarding how to behave and feel in those situations. This is referred to as social referencing, a concept closely tied to modeling (Morris et al., 2007) and another common way children learn about emotions. 
Lastly, parents may also socialize emotions by how they respond when their children have an emotional experience. Parents could help the child with his or her emotions, giving them suggestions to cope or providing emotional support, or instead they could exacerbate the situation and punish the child (Eisenberg et al., 1998; Fabes et al., 2002). One conceptualization of adaptive parental responses is emotion coaching style, which often results in positive outcomes for children (Gottman et al., 1996; Gus et al., 2015; Katz \& Hunter, 2007; Ramsden \& Hubbard, 2002). Emotion coaching is a more complex and higher quality method of emotion socialization (Gottman et al., 1996) where it helps children tolerate negative affect, to regulate their emotions, and to focus social attention, which ultimately helps foster socially skilled behavior (Gottman et al., 1996). In contrast, punitive reactions to children's affect have been linked to inappropriate emotion regulation strategies and overall negative outcomes (Morris et al., 2007). Supportive parental reactions to children's emotions are important for positive emotions as well as negative (Gentzler, Ramsey, \& Black, 2015; Katz, Shortt, Allen, Davis, Hunter, Leve, \& Sheeber, 2014; Yap et al., 2008). Overall, adaptive parental responses to children's emotions, including emotion coaching, is associated with less internalizing symptoms whereas their punishing and neglectful responses are associated with emotional and behavioral problems for children (Katz \& Hunter, 2007; Klimes-Dougan et al., 2007; Stocker, Richmond, Rhoades, \& Kiang 2007).

Perhaps another avenue from which parents can learn ways to cultivate graitude is by examining psychological interventions (Owens \& Patterson, 2013; Seligman, Steen, Park, \& Peterson, 2005). For example, in a study conducted by Froh, Kashdan, Ozimkowski, and Miller (2009a), the "gratitude visit" intervention was examined with children and adolescents aged 8 to 19. Participants in the control group wrote about a trivial event, while those in the gratitude 
condition wrote a thank-you letter they eventually read to the recipient. The findings revealed that participants in the gratitude condition reported more gratitude and positive affect at posttreatment (Froh et al., 2009a). In another study conducted by Froh and colleagues (2014), children (8 to 11 years) were randomly assigned to either a control group or an experimental group that educated children about appraisals of benefit exchanges. Children were introduced to a benefit appraisal curriculum that induced grateful thinking (assessing aspects of benefit appraisal such as intent, cost, and benefit). Grateful thinking was assessed with appraisal-benefit vignettes where students visualize themselves as the main character of the story. This weekly intervention session engendered feelings of gratitude five months later and had a significant positive effect on children's well-being (Froh et al., 2014). Considering this prior research, it is clear that gratitude development is crucial during childhood (Froh et al., 2010; Froh et al., 2011a; Froh et al., 2011b; Graham \& Weiner, 1986; Tian et al., 2014) and suggests that gratitude is malleable in youth. Thus, research on gratitude socialization may open doors for psychologists to implement additional gratitude interventions and can add to knowledge on how parents can promote gratitude in their children. These efforts could increase children's level of gratitude and potentially result in positive outcomes like greater well-being, quality of peer friendships, and social skills (Bono, Froh, \& Forrett, 2009).

Although research on the socialization of gratitude is limited, research does show that parents are instrumental in helping their children understand the concept of gratitude and to say 'thank you' when appropriate (Gleason \& Weintraub, 1976). Applying research on emotion socialization more generally, some of the ways that parents could potentially socialize gratitude with their children is through discussions that explain the concept of gratitude to their children, engaging in appreciative behavior and talk that can be modeled by their children, and lastly, 
encouraging activities and discussion with daughters and sons that help promote gratitude understanding and expression (Halberstadt, Langley, Hussong, Rothenberg, Coffman, Mokrova, \& Costanzo, 2016).

Because gratitude is a complex emotion and involves both emotion and action, there are multiple components of gratitude that parents could be socializing. According to Halberstadt and colleagues, there are three main components of gratitude: emotional, cognitive, and behavioral (Halberstadt et al., 2016). The emotional element of gratitude encompasses the simultaneous increase of positive feelings such as joy, happiness, and benevolence, and the decrease of negative emotions such as sadness and resentment (Emmons \& McCullough, 2003). The cognitive element of gratitude involves an individual's judgment or belief about the benefits associated with a grateful act and that there is an external source (the benefactor) who is responsible for this (Clore, Ortony, \& Foss, 1987). Regarding the behavioral component of gratitude, this can include both verbal communication, and a physical demonstration or expression of gratitude (Emmons \& McCullough, 2004). For example, an individual may thank someone to show gratitude, but someone else could present a gift or return a favor as a demonstration of their gratitude. However, more research is necessary to determine what types of behaviors constitute an act of gratitude and how researchers make these decisions. Furthermore, research has not examined which method of gratitude socialization is the most effective in parent-child dyads. Currently, the only study examining how gratitude may be socialized was conducted by Rothenberg and colleagues who focused on examining niche selection as a method of socialization (Rothenberg et al., 2017). The findings of the study showed that parents often teach their children about gratitude by involving them in activities that allow the cultivation of gratitude such as volunteering in a soup kitchen (Rothenberg et al., 2017). However, this 
research is limited. To add to the literature, the current study applies parental emotion socialization research to the socialization of gratitude and uses both quantitative data (questionnaires) and qualitative data (coded discussions about gratitude) to highlight potential ways that parents can teach their children about gratitude and whether some methods seem to work better than others.

\section{Research Questions and Hypotheses}

\section{Research Question 1}

Do parental gratitude socialization behaviors relate to children's level of gratitude?

Hypothesis 1a. Effective socialization of children's gratitude during a discussion task will be positively associated with children's understanding and frequency of gratitude (reported during the discussion or on a questionnaire).

Hypothesis 1b. Parents' encouragement of children’s gratitude on a questionnaire, assessed via mother report and child report, will be positively associated with children’s understanding and frequency of gratitude (reported during the discussion or on a questionnaire).

Hypothesis 1c. Parents’ own understanding of gratitude, as reported on a questionnaire, will be positively associated with children's understanding and frequency of gratitude (reported during the discussion or on a questionnaire).

\section{Research Question 2}

Does children's gratitude relate to their socio-emotional functioning (depressive symptoms, well-being, and social skills)?

Hypothesis 2a. Children with a higher level of gratitude understanding and frequency will report lower levels of depressive symptoms. 
Hypothesis 2b. Children with a higher level of gratitude understanding and frequency will have higher levels of well-being, as by a mother-reported positive affect scale.

Hypothesis 2c. Children with a higher level of gratitude understanding and frequency will have higher social skills (using a composite variable of mother-reported subscales).

\section{Research Question 3}

Does parents' socializing behavior of gratitude directly and indirectly relate to child outcomes through its effect on children's gratitude?

Hypothesis 3a. Effective socialization of children's gratitude is expected to relate to child outcomes measured through its effect on children’s gratitude.

\section{Research Question 4}

Is the proposed mediation model moderated by children's age?

Hypothesis 4a. The proposed mediation model will be stronger for older children for the path from the predictor (parent socialization of gratitude) to mediator (children's understanding of gratitude) and the mediator to the outcomes (children’s global well-being and social skills).

\section{Method}

\section{Participants}

A total of 100 mother-child dyads participated in the original study. For the current project, 95 dyads were included. The remaining 5 dyads were excluded due to missing survey data, missing video data, or unreliable parent or child data (e.g., one dyad was removed from analyses due to mothers' lack of English language proficiency, two dyads were removed for missing video data, and lastly, two dyads with missing survey data were removed). Participants were mother-child dyads recruited from the Morgantown area. The children were between the ages of 7 and 12. Participants' sociodemographic characteristics reflect the area (e.g., mainly 
white, moderate family income; see Table 1). A power analysis had been conducted using G*Power (Erdfelder, Faul \& Bechner, 1996; Faul, Erdfelder, Lang, \& Buchner, 2007) to calculate the required sample size for the current study, and it suggested that for a multiple regression analysis, with a significant medium effect $\left(f^{2}=.15\right)$ at $p<.05$, that $N=77$ would be sufficient to achieve a power of $80 \%$ with a total of 5 predictors. Thus, we have met this requirement with the 95 dyads.

\section{Procedure}

Participants were recruited from small towns located in West Virginia, United States via the use of flyers, emails, news outlets, and in-person recruitment at community events. Participants were able to either complete the study in a research laboratory at West Virginia University (WVU) or in their home. Mothers and children were provided consent and assent forms to ensure voluntary participation. Mothers and children completed questionnaires separately. Additionally, the participants took part in two discussion tasks that were video recorded. For the purposes of the current study, the focus is on the second discussion task that prompts the mother-child dyads to engage in a five-minute conversation about gratitude. Families received $\$ 30$ for their participation.

\section{Measures}

Demographics. Mothers completed a demographics questionnaire that examined participant age, gender, and race/ethnicity. Mothers also answered additional questions regarding household income, level of education, marital status, partner's education, and religion. Potential covariates considered for the current study were children's gender and age participating in the study.

Socialization of Gratitude (Appendix A) 
Mothers' own gratitude. The Positive Events and Responses Survey for Adults (PEARS-A; Ramsey \& Gentzler, 2014) is a modified version of the original measure (PEARS) that was validated with college students (Gentzler et al., 2015). The PEARS-A uses vignettes to assess mothers' hypothetical emotional and behavioral responses to six vignette-based positive events (two interpersonal events, two achievement-related events, and two pleasant surprises). An example event is: "You just reached your exercise goal that you have been working toward for a long time. It was hard work but it was a goal that you really wanted to reach.” Mothers responded to all six hypothetical events using a 5-point Likert scale $(0=$ not at all to $4=$ very likely). Using a single item from all six events ("How likely would you be to... be thankful that this event happened?”), we created a mean score $(\alpha=.58)$ so that higher scores indicated that mothers reported being more likely to respond to the vignettes being thankful or grateful, tapping into parental modeling behavior specifically.

Mothers' encouragement of gratitude (mother-report). The Parents’ Responses to Children’s Positive Events (PRCPE; Gentzler, Ramsey, \& Black, 2015) measure was used to assess how mothers responded to potential positive events their children might experience. This particular measure was also created using the original PEARS questionnaire (Gentzler et al., 2015). Mothers read five hypothetical positive events and were asked to imagine that each happened to their child. An example event is: "Your child comes home from school and just found out that he/she received an A in his/her most difficult class in school. Your child has been working hard for weeks.” Mothers responded to various responses using a 5-point Likert scale (0 = not at all to 4 = very likely). Each gratitude item (e.g., "How likely are you to... encourage your child to be grateful for his/her good grade?”) across five vignettes were averaged ( $\alpha=.85)$, so that higher scores indicated that mothers reported being more likely to encourage their child to 
be grateful or thankful for the positive events, tapping into parent's responses to their child's positive events and emotions.

Mothers' encouragement of gratitude (child-report). The Parents’ Responses to Children's Positive Events (PRCPE-Y) was used to examine mothers' responses to children's' positive events from the perspective of the child. The PRCPE-Y was adapted from the original measure and designed for children to complete. However, this measure does not involve the use of scenarios. The PRCPE-Y instructs children to respond to 11 items in terms of how their mothers generally would respond to these events. The two scales typically derived from this measure assess the likelihood of their mother to encourage savoring and dampening responses (tapping into mother socialization). However, for this study, a single item was examined: "How likely is your MOTHER to... encourage you to be grateful or thankful for the good event?”. Children responded to this item using a 5-point Likert scale ( $0=$ not at all to $4=$ very likely).

Discussion task coding. For the gratitude discussion, mothers and children were asked to discuss gratitude for 5 minutes by addressing three prompted topics: 1) children's opinion on gratitude, 2) mothers’ opinion on gratitude, and 3) children’s and mothers' combined view on whether they feel gratitude enough and ways to increase gratitude. Mothers and children each answered three questions regarding their opinion on gratitude: 1) What is gratitude? 2) What does it feel like? and 3) What makes you feel grateful or thankful? In order to measure socialization of gratitude, existing codes were used in addition to new codes that were developed and coded to assess socialization of gratitude. Regarding existing gratitude codes, four indices of gratitude socialization were tapped into regarding gratitude definitions and gratitude examples.

Gratitude definitions. Mothers’ definition of gratitude was considered as a socialization variable as they were asked to give their own definition of gratitude after their children’s 
definition (see Table 2). Specifically, two variables were created to represent mothers' definition of gratitude. First, mothers’ responses to the question “what is gratitude?” were coded using a 7point coding scheme, where higher scores indicated a more advanced understanding of gratitude. Thus, mothers' definition was assigned a code based on the most advanced definition (see Table 2) of gratitude provided by mothers. Second, mothers' definition by examples were also given a code for the highest level of gratitude example (see Table 3) they provided using the same 7point scale mentioned previously to assess their level of socialization skills. This was based on their answer to the third question in the prompt asking them what they are grateful for. There was acceptable interrater reliability for these codes (see Table 2 and 3).

Gratitude examples. Additionally, two numerical counts were also created to examine examples of gratitude mothers provide (see Table 3). First, the total number of gratitude examples mothers shared in the video was counted and used as a socialization variable, hereby a higher number of examples in total represent a better understanding of gratitude. Second, we examined the amount of "higher-order level" gratitude examples that mothers reported, where higher numbers of higher-order gratitude examples represent a more advanced understanding of gratitude, potentially contributing to more “effective” gratitude socialization. Higher-order level examples of gratitude fall under the category of "Intangible things" (contact the author for coding development and measures). Specifically, examples of "Intangible things" include gratitude for a higher power/being, good health, peace, and personal growth. Other types of commonly provided examples are "People” (e.g., family members, friends, and teachers) and “Tangible things” (e.g., materialistic objects, accomplishments, birthdays, and pets).

Gratitude global code. Finally, we created a coding scheme for a global code reflecting mothers' elaboration of gratitude to examine mother's socialization of gratitude. Coding was 
completed following the viewing of the videotape based on the overall interaction between mother and child using a Likert type scale ranging from 1 to 4 . Higher scores indicated that mothers provided substantial insights into the meaning of gratitude and why it is important and elaborated on the children's statements about it, whereas lower scores reflect mothers who offered little to no explanation or elaboration on the concept of gratitude and its importance. Inter-rater reliability for this global code was high, ICC $=.84$.

Additional codes. Two additional codes were created but were not used in analyses (please contact the author for copies of coding development and measures). The first code was created to tap into how gratitude feels. Participants were asked how gratitude feels like as part of the discussion task, so answers were written down and stored for future analyses. However, at least $25 \%$ of the sample did not respond to this question and the rest of the responses consisted of mainly answers such as "happy”, "good”, or "thankful”. Due to a lack of variability in participants' answers we did not analyze this code with main study variables. The second code was created to tap into what gratitude looks like, coding for nonverbal communication in the form of facial expressions (e.g., smiling, eye contact) and physical expressions (e.g., light tap, hugging) displayed by participants. When the child or mother was specifically talking about gratitude pertaining to each other or their family member (mom being grateful for child/family; child being grateful for mother/family), participants received an individual code every time participants mentioned and responded to gratitude for each other or family members. These codes were then averaged to create an overall score for how gratitude looks like. ICC's were acceptable for facial expressions when mothers mentioned gratitude $=.79$, whereas ICC's were lower when mothers responded to children's expression of gratitude $=.51$. This pattern was identical for children with ICC's high for gratitude mention $=.91$, and lower for gratitude 
responses $=.67$. This suggests that gratitude may look different and is easier to detect when individuals state what they are grateful for in comparison to how they look when someone expresses gratitude for them. However, there was also a lack of variability in the facial and physical expressions participants displayed and at least $30 \%$ of participants did not provide examples of gratitude for each other or family members as the coding scheme required. Most participants received either a 0 or a 2 code for facial and physical expression; where 0 represented no visible facial or physical expressions and 2 represented substantial positive expressions overall. With the limited amount of participant data and lack of variability in responses, we decided not to use this code in analyses.

Children's Gratitude (Appendix A)

Children's own gratitude. The Positive Events and Responses Survey for Youth (PEARS-Y; Gentzler \& Palmer, 2014), was created based on the original PEARS measures (Gentzler et al., 2015) to assess children's emotional and behavioral responses to five vignettebased positive events about themselves. An example event is: "You just found out that you received an A on your report card in your hardest class at school. You had studied a lot and really hoped you would do well”. A single item was used for the current project: "How likely are you to... feel grateful or thankful about your grade?”. Children responded to this item using a 5point Likert scale $(0=$ not at all to $4=$ very likely $)$ with moderate internal consistency at $\alpha=.58$. The gratitude items were averaged across the five vignettes to create an overall score representing children's level of gratitude frequency (tapping into gratitude understanding) by means of gratitude experience (i.e., feeling grateful).

Discussion task coding. To assess children's understanding of gratitude, coded variables from the gratitude discussion task were used. First, children’s definition of gratitude was coded 
as two separate variables to represent understanding of gratitude. This coding process was identical to that of their mother's code for definitions of gratitude (see above). Then, we assessed children's understanding and frequency of gratitude by counting the number of times children mentioned something they were grateful for and the number of higher-order or advanced examples provided by the child specifically. Additionally, we created a global code reflecting children's understanding of gratitude (please contact the author for copies of coding schemes). This coding was completed following the viewing of the videotape based on the overall interaction between mother and child using a Likert type scale ranging from 1 to 4 . Higher scores for understanding gratitude indicated children have gained a substantial level of understanding from mothers and they even added to the discussion by providing their own unique or novel examples/definitions, whereas lower scores reflect children who ignore the topic of gratitude, seem disengaged and uninterested in discussing gratitude, and/or change the topic of conversation. Inter-rater reliability for this global code was high, ICC $=.897$. This global code taps into the elements of gratitude in a similar fashion to mothers' global code. Lastly, two additional codes were created for children to tap into how gratitude feels and looks like, following the same procedure that blind coders used to assign codes for mothers (see Table 2 and 3). These codes were not used in analyses for the current study due to limited variability in participant data as discussed earlier regarding coded variables for mothers.

Child Outcomes (Appendix B)

Depressive symptoms. The Center for Epidemiological Studies - Depression Scale Children (CES-DC; Faulstich et al., 1986; Weissman et al. 1980) is a 20-item measure that was used to assess children's levels of current depressive symptoms. Higher scores on the measure denote increasing levels of depression for children. A cut-off score of 15 was determined to 
indicate clinical levels of depressive symptoms in children and adolescents (Weissman et al., 1980), however, the scale was used as a continuous variable. Children responded using a 4-point Likert scale ranging from $(0=$ not at all to $3=a$ lot $)$ with acceptable internal consistency at $\alpha=$ .80. Example items include: “I wasn’t able to feel happy, even when my family or friends tried to help me feel better." and "I felt like I was too tired to do things."

Positive affect. The Affect Valuation Index (AVI; Tsai \& Knutson, 2006) was utilized in the current study to measure children's positive affect. For this study, children's frequency of moderate-arousal positive affect (positive emotions: happy, content, and satisfied) was examined. The directions asked mothers to rate how often their children actually experienced those emotions across a typical week using a 5-point Likert scale ranging from $(1=$ never to 5 = all the time) with high internal consistency at $\alpha=.84$.

Social skills. The Social Skills Improvement System (SSIS; Gresham \& Elliot, 2007) is a 79-item measure that examines multiple constructs of social skills in children and adolescents. For the current study, mothers reported on children's social skills or strengths for the following domains: (assertiveness; communication; cooperation; empathy; engagement; responsibility; self-control; and problem behaviors (e.g., internalizing and externalizing). A composite score was created and used to assess social skills as a whole. Internal consistency reliabilities for both social skills and problem behavior scales were acceptable (from $\alpha=.78$ to $\alpha=.91$; overall measure reliability was also acceptable at $\alpha=.80$ ). Mothers indicated the frequency with which their children displayed each social skill and problem behavior in the past two months using a 4point scale ( 1 = never to 4 = almost always). Some example items include: "Fights with others", “Follows rules when playing games with others”, and "Keeps others out of social circles.” To create the social skills scale based on prior research (Gresham \& Elliot, 2007). 


\section{Results}

\section{Preliminary Analyses}

Data from a total of 95 mother-child dyads were used in the following analyses.

Descriptive statistics for all participants can be found in Table 1. Analyses for the current study were conducted to evaluate issues of missing data and assumptions of linear regression. All predictor, mediator, and outcome variables were analyzed for missing data, followed by univariate, bivariate, and multivariate statistics. We utilized the SPSS program Missing Value Analysis 7.5, an expectation maximization (EM) technique to examine missing data. Little’s MCAR test was also conducted, which resulted in a non-significant chi-square value; $\chi^{2}=$ 180.62, $d f=169, p=.256$, indicating that data was missing completely at random (MCAR). Missingness was either at or less than $5 \%$ for all variables of interest so data for five participants was removed from further analyses with no imputations made to the data set.

Exploratory data analyses were also run to assess normality, homoscedasticity, and multicollinearity. After examining the data set, there was no evidence of multicollinearity, as assessed by Pearson correlation $(|r|<0.9)$. Additionally, all variables met acceptable guidelines with tolerance values above .2, VIF values below 10, and the average of the VIF values was not considerably greater than 1 . There were no univariate outliers for any of the main variables, as assessed by inspection of a boxplot, and no multivariate outliers in the data, as assessed by Mahalanobis distance $(p>$.001). Most variables were normally distributed, as assessed by Shapiro-Wilk's test $(p>.05)$ and there were no Cook's Distance values above 1 . Although a few key variables (Likert scale definition of gratitude, children’s own gratitude (PEARS-Y), mothers’ likelihood to encourage gratitude (self-report: PRCPE-A), and mothers' likelihood to encourage gratitude (child-report: PRCPE-Y) were not normally distributed, regression analyses 
were still run as this statistical test is fairly robust to non-normality and these variables were only moderately skewed and kurtotic. Furthermore, square root transformations were made for skewed variables to see if there was a difference in data findings, however, there were none so the original data was used. Lastly, there was homoscedasticity, as assessed by visual inspection of a plot of studentized residuals versus unstandardized predicted values.

A series of preliminary analyses were conducted to identify associations between demographic variables and main variables of interest (see Table 4 and 5). First, it was found that mothers' education and religious importance were associated with mothers' socialization of gratitude. Specifically, more educated mothers had more complex definitions of gratitude, higher levels of gratitude elaboration with their children, and higher levels of own gratitude (see Table 4). Furthermore, the more importance mothers placed on religion, the more they encouraged their kids to be grateful, and the higher levels of gratitude they had. Furthermore, more educated mothers reported that their children had higher social skills, communication skills, and lower levels of problem behaviors (see Table 5). Next, an independent samples t-test revealed a significant mean difference for child gender for typical positive affect, $t(90)=2.37, p=.020$, whereby mothers reported higher levels of typical positive affect for daughters $(N=42, M=$ 3.10, $S D=.68)$ as compared to sons $(N=50, M=2.77, S D=.68)$. Further independent samples t-tests revealed a significant gender difference for the total amount of gratitude examples provided by children, $t(92)=2.33, p=.022$, whereby girls $(M=6.53, S D=3.51)$ reported more examples than boys $(M=4.92, S D=3.21)$. Thus, we entered gender as a covariate in subsequent analyses.

Additionally, bivariate correlations within constructs were examined (Tables 6, 7 and 8). Significant mono-method correlations were present for mothers' socialization variables for both 
survey and discussion data, however, no cross-methods correlations reached significance.

Similarly, significant mono-method correlations were present for mediator variables (children's gratitude understanding), but only with observational data. Regarding outcome variables, positive affect was positively associated with social skills, and both social skills and communication were negatively associated with problem behaviors. However, these motherreported scales were not correlated with children-reported depressive symptoms.

An age difference was expected for all outcome variables for children. Significant correlations between children's age and key variables include positive associations between the number of higher-order examples of gratitude given by children, their definition of gratitude based on a Likert scale, and mother's own gratitude. Specifically, as children's age increased the number of higher-order examples of gratitude provided by children also increased $(r=.24)$ in addition to the level of sophistication of their definitions of gratitude $(r=.22)$. Additionally, as children's age increased the number of depressive symptoms they reported decreased $(r=-.23)$. Given the correlations with age and because age was expected to moderate paths in mediation models, child age also was entered in all regression analyses.

Bivariate correlations were assessed among all main independent and dependent variables and proposed mediators. Only variables showing significant correlations were used in subsequent mediation and moderated mediation analyses. First, in terms of the predictor variables’ associations with the mediating variables (mother socialization and children's gratitude), bivariate correlations indicated that within the discussion task data, the total amount of gratitude examples mothers provided, the total number of higher-order examples mothers provided, and mother's definition of gratitude based on their most advanced gratitude example was positively significantly correlated with all child corresponding variables (see Table 9). Additionally, the 
total number of gratitude examples mothers provided was also positively significantly correlated with the total number of advanced gratitude examples children provided and their gratitude definition based on their most advanced example. Next, mother's number of advanced gratitude examples was positively significantly correlated with children's total number of gratitude examples and their gratitude definition based on their most advanced example. Finally, children's report of mother's encouragement of gratitude is also significantly correlated with children's own report of gratitude. Although both child-report, it suggests that children who perceive their mothers to encourage gratitude also reported higher levels of gratitude.

Additionally, mother's elaboration of gratitude (global code) was positively significantly correlated with children's understanding of gratitude, indicating that more elaborate discussions of gratitude are associated with a better of understanding of gratitude by children. Next, mothers' elaboration of gratitude positively significantly correlated with mothers' report of children's social skills and communication, whereby higher levels of gratitude elaboration were associated with higher levels of social skills and communication for children (see Table 11). Furthermore, mother's elaboration of gratitude was negatively positively correlated with problem behaviors. Additionally, mothers' elaboration of gratitude and their own levels of gratitude were significantly correlated with their reports of children's social skills, communication, and problem behaviors, in the same direction as previously mentioned. Finally, mother's own gratitude was positively significantly correlated with their report of their children's social skills.

Finally, in terms of associations between children's gratitude and outcomes a similar result was found, whereby higher levels of gratitude understanding (assessed in the discussion task) were associated with higher levels of social skills and communication for children as 
reported by their mothers (see Table 10). Thus, both children's social skills overall and communication skills were used as outcome variables in subsequent models.

\section{Primary Analyses}

According to Baron and Kenny (1986), four steps must be met for mediational analysis, and that a relationship must exist between the predictor variable and the mediator and between the mediation variable and the outcome variables. However, many contemporary researchers argue that not all steps are necessary for mediation, but instead serve as a starting point for examining mediational hypotheses (MacKinnon, Fairchild, \& Fritz, 2007). In the current study, Hayes PROCESS is used to examine indirect effects with the use of bootstrapping techniques (Shrout \& Bolger, 2002) and the Sobel Test (Sobel, 1982). Bootstrapping is a non-parametric method based on resampling with replacement done numerous times (e.g., 5000), whereas the Sobel Test is a more conservative method of testing whether the mediator carries the influence of a predictor to the outcome. Age and gender were entered as covariates in all analyses to account for any change in outcome variables not associated with main predictor variables. Age was also examined as a moderator for significant regression analyses. Multiple regression analyses with all variables entered can be found in Tables 12 and 13.

\section{Regression Analyses}

Hypothesis one. To analyze hypothesis one, that maternal socialization of gratitude would significantly predict children's gratitude understanding (examining path A in a mediation model), five multiple regression analyses were conducted. All eight predictors were entered as independent variables in the model along with child gender and child age to predict each mediator variable (see Table 12). Regression analyses were conducted separately for each predictor, however, for the sake of parsimony, findings are reported from analyses including all 
predictors. All models still hold when predictors are entered into the model. The first model with children's own gratitude (PEARS-Y) entered as the dependent variable was significant; F (10, $85)=7.14, p<.001 . R^{2}$ for the overall model was $43.0 \%$ with an adjusted $R^{2}$ of $37.0 \%$, a moderate size effect according to Cohen (1988). The analysis showed that although most variables were not significant predictors of children's own gratitude (PEARS-Y), child's report of mother's likelihood to encourage gratitude (PRCPE-A) was (Table 12).

In the second model, children's overall definition of gratitude was entered as the dependent variable. The full model was marginally significant; $F(10,85)=1.99, p=.05 . R^{2}$ for the overall model was $17.4 \%$ with an adjusted $R^{2}$ of $8.7 \%$, a small size effect according to Cohen's rule of thumb. The analysis showed that none of the variables significantly predicted children’s overall definition of gratitude (see Table 12).

Regarding the third regression model, children's understanding of gratitude was entered as the dependent variable. The full model was marginally significant; $F(10,85)=1.84, p=.073$. $R^{2}$ for the overall model was $16.3 \%$ with an adjusted $R^{2}$ of $7.4 \%$, also a small effect size. The analysis shows that although the overall model did not have variables that significantly predicted children's understanding of gratitude, mother's elaboration of gratitude (global code) $(\beta=.36, t=$ 3.46, $p<.001$ ) significantly predicted children's understanding of gratitude (see Table 12).

In the fourth model, the total number of gratitude examples given by children was entered as the dependent variable. The full model was statistically significant; $F(10,85)=2.03, p=$ .046. $R^{2}$ for the overall model was $17.7 .0 \%$ with an adjusted $R^{2}$ of $9.0 \%$. The analysis revealed that variables did not significantly predict the total number of examples given by children (see Table 12). However, children’s gender was marginally significant $(p=.061)$ in predicting the 
total number of gratitude examples provided by children, whereby female children provided more examples of what they were grateful for as compared to male children.

Finally, the fifth model examined the total number of higher-order examples of gratitude given by children as the dependent variable. The full model was marginally significant; $F$ (10, $85)=1.89, p=.064 . R^{2}$ for the overall model was $16.7 \%$ with an adjusted $R^{2}$ of $7.9 \%$, a small effect size. The analysis revealed that predictors did not significantly predict the total number of higher-order examples given by children (see Table 12). However, child’s age was marginally significant ( $p=.061$ ), whereby older children (ages 10 to $12 ; M=2.34, S D=2.30$ ) provided more examples of higher-order gratitude (e.g., god, shelter, feeling fortunate, etc.) than younger participants $(M=1.81, S D=1.81)$.

Hypothesis Two. To analyze hypothesis two, four multiple regression analyses were run to examine whether mediator variables (children's understanding of gratitude) predicted child outcome variables (examining path $\mathrm{b}$ in a mediation model). All six predictors were entered as independent variables in the model along with gender and age (see Table 13). A separate model was run for each dependent variable. The first model, with children's self-reported depressive symptoms was entered as the dependent variable was not statistically significant, $F(8,87)=$ $1.67, p=.127 . R^{2}$ for the overall model was $11.8 \%$ with an adjusted $R^{2}$ of $4.8 \%$. The analysis showed that although most of the variables did not significantly predict child's depressive symptoms, child gender $(\beta=.22, t=2.03, p=.045)$ did, whereby boys $(M=.95, S D=.36)$ reported more depressive symptoms than girls $(M=.79, S D=.39)$. Additionally, child age was marginally significant $(\beta=-.22, t=-1.99, p=.05)$, whereby younger children $(M=.92, S D=$ $.42)$ reported more depressive symptoms than older children $(M=.79, S D=.27)$. 
In the second model, children's communication skills was entered as the dependent variable. The full model was not significant; $F(8,87)=1.39, p=.221 . R^{2}$ for the overall model was $10.0 \%$ with an adjusted $R^{2}$ of $2.8 \%$, a small effect size. The analysis showed that although none of the variables were significant predictors of children's communication skills, children's understanding of gratitude (global code) $(\beta=.31, t=2.77, p=.007)$ was, which indicated that children who better understand gratitude also have better communication skills (see Table 10).

Regarding the third regression model, children's problem behaviors was entered as the dependent variable. The full model was not significant; $F(8,87)=1.31, p=.26 . R^{2}$ for the overall model was $9.5 \%$ with an adjusted $R^{2}$ value of $2.2 \%$, which also indicated a small effect size. The analysis showed that there were no significant predictors (regarding mediator variables) of parent-reported child problem behaviors (see Table 13).

Finally, the fourth model examined typical positive affective in children as the dependent variable. The full model was not significant; $F(8,87)=1.46, p=.20 . R^{2}$ for the overall model was $10.5 \%$ with an adjusted $R^{2}$ of $3.3 \%$. The analysis revealed that there were no significant predictors (regarding mediator variables) of child typical positive affect (see Table 13).

\section{Mediation Analyses with Child Understanding}

Based on significant regression analyses, we performed multiple mediation analyses using PROCESS model 4 to analyze hypothesis three. Only one mediation model was significant. Specifically, PROCESS model 4 was used to investigate the hypothesis that children's understanding of gratitude mediates the effect of mother's elaboration of gratitude on children's social skills. Results indicated that mothers' elaboration of gratitude was a significant predictor of children's understanding of gratitude, $b=.43, S E=.12, p<.001$, and that children's understanding of gratitude was a significant predictor of children's communication skills, $b=$ 
$.96, S E=.47, p=.04$. Furthermore, mothers' elaboration of gratitude was a statistically significant predictor of children's communication skills, $b=1.47, S E=.56, p=.01$. These results support the mediational hypothesis. Mothers' elaboration of gratitude was no longer a significant predictor of children's communication skills after controlling for the mediator (children's understanding of gratitude), $b=1.06, S E=.59, p=.076$, (Figure 1). The indirect effect, tested using a bootstrap estimation approach with 5000 samples, indicated the indirect coefficient was significant, $b=.42, S E=.23,95 \%$ CI $[.06, .96]$.

\section{Moderated Mediation with Child Understanding and Age}

To test hypothesis four to determine if effects were stronger for older children, we used conditional process modeling to test for moderated mediation as outlined by Hayes (2013) using the PROCESS macro. Specifically, we tested whether child age moderated the associations among mother's elaboration of gratitude (global code), children's understanding of gratitude (global code), and children's communicative social skills (this model corresponds to Model 58 in Hayes, 2013, which tests for moderation at each path). According to this model, moderated mediation occurs when either path a (mothers' socialization method to children's understanding of gratitude), and path b (children's understanding of gratitude to child outcomes) are moderated (Edwards \& Lambert, 2007). The direct path between predictor and outcome is not expected to be moderated by age since this path is unexplored and considered exploratory in these analyses. With age as the moderator it was expected that the mediation model would be stronger for older children. This was expected for all key variables and thus, moderated mediation models were conducted for all models. Furthermore, models were also run using model 59 (tests for moderation at path a and path b only), but no differences emerged in findings so results from model 58 are discussed. However, only significant models are reported here. 
The model predicting children's understanding of gratitude was significant, $F(3,91)=$ 4.17, $p=.008, R^{2}=.12$. Only mother's elaboration of gratitude $(b=.44, S E=.124, p<.001)$ was a significant predictor of children's understanding of gratitude. Child's age $(b=-.00, S E=$ $.05, p=.95$ ), and the interaction between mothers' elaboration of gratitude and child's age (path $\mathrm{a} ; b=.03, S E=.09, p=.79)$ were non-significant. The overall model predicting children's communication skills was significant, $F(4,90)=3.53, p=.01, R^{2}=.14$. However, child's age did not significantly moderate the link between children’s understanding of gratitude and children's communication skills (path $\mathrm{b} ; b=.51, S E=.31, p=.09$ ). It is important to note however, that the moderation was marginally significant and in the hypothesized direction. Specifically, the conditional indirect effects indicated that the association between children's understanding of gratitude and children's communication skills was not significant for younger participants (one SD below the mean age), $b=.09, S E=.26,95 \%$ CI [-.35, .69], but the association between child gratitude understanding and communication skills was significant for older participants (one SD above the mean age), $b=.78, S E=.42,95 \%$ CI $[.13,1.85]$.

\section{Discussion}

The present study tested multiple hypotheses to examine the association between mother's socialization of gratitude, children's gratitude, and several child outcomes (i.e., wellbeing, depressive symptoms, and social skills). Overall, it was found that numerous predictor, mediator, and outcome variables were associated. However, only one significant mediation model emerged, whereby mother's socialization of gratitude was associated with higher levels of communication for children through the mechanism of children's understanding of gratitude. Only the path from children's understanding of gratitude to communication was moderated by age, whereby older children who understood gratitude benefited from higher communication 
skills, indicating that a better understanding of gratitude is more likely to yield significant associations with positive outcomes. These findings are consistent with the hypothesis of the current study that states effective socialization of children's gratitude is expected to relate to child outcomes measured through its effect on children's understanding of gratitude. However, the current study lacked significant findings that connect mother's socialization of gratitude with children's gratitude across reporters (e.g., mother-report predicting child-report) for other main study variables. Overall, the current study serves as a starting point for research examining parental socialization methods effective for teaching children about gratitude.

\section{Mothers' Elaboration of Gratitude and Children's Gratitude}

Prior research has shown that parents play a large role in helping their children understand both the experience and expression of emotions (Eisenberg et al., 1998; Fredrickson, 1998; Gentzler et al., 2015; Morris et al. 2007; Zahn-Waxler, 2010). However, in relation to the first hypothesis that mother's socialization of gratitude would be associated with children's gratitude, the results are inconsistent. Specifically, mothers' socialization of gratitude significantly predicted children's own gratitude in response to hypothetical positive vignettes (PEARS-Y). However, only children's report of mother's likelihood to encourage gratitude (PRCPE-Y) significantly predicted children's own gratitude (PEARS-Y). Although this finding indicates maternal socialization is associated with children's own levels of gratitude, both measures were completed by children and therefore could stem from children's perceptions of their mothers' socialization behaviors as opposed to actual socialization methods utilized by mothers. Thus, the results would be more compelling if mothers' report of their encouragement of gratitude also predicted children's own gratitude. In the current study, mother's socialization and children's gratitude were measured in multiple ways including the use of surveys and coded 
qualitative data. However, the gratitude discussion task was not independent for mother and child and thus, the use of non-independent variables could result in shared method variance as it was impossible to tease apart the influence of mother's opinion of gratitude from those of their children. Potential reporter and method biases in the current study indicate the importance of ensuring different sources for reporting on key variables. The strength of association between two constructs may be inflated when these variables are reported by the same person. Thus, utilizing Structural Equation Modeling with latent variables may help determine the unique contribution of each construct by teasing apart the method variance from the construct variance.

Furthermore, mothers’ socialization of gratitude marginally predicted children’s overall definition of gratitude. Although the overall model was marginally significant, mothers’ socialization methods did not individually predict children's overall definition of gratitude. To our knowledge no other study has examined parental socialization predicting children’s definitions of gratitude. Thus, other methods of emotion socialization not specifically examined in the current study might be better predictors of children’s overall definition of gratitude (e.g., recurrent emotion discussion; Eisenberg et al., 1998). Similarly, mothers’ socialization of gratitude marginally predicted children's gratitude. Although the overall model was marginally significant, mother's elaboration of gratitude (global code) significantly predicted children’s understanding of gratitude (global code). This finding is vital because it highlights the importance of parent's engagement in emotion discussion with their children. Emotion discussion is a common method of emotion socialization utilized by numerous socialization agents and aids children in potentially better understanding emotions by conversing about the emotion itself, what it means, and when it is appropriate to display (Eisenberg et al., 1998). In the present study, mothers' elaboration of gratitude tapped into the extent to which mothers 
provided considerable insights into the meaning of gratitude and helped their children think of gratitude in new ways. Currently, there is a lack of research examining parental socialization of gratitude, but some researchers suggest parents can help their children understand gratitude by engaging in conversations with them about the construct (Bono \& Froh, 2009) and placing their children in gratitude-eliciting situations such as family dinners (where children the opportunity to say thank you for the meal that was created and appreciate the effort it took to create) or community events, such as volunteering in soup kitchens (Rothenberg et al., 2017).

Furthermore, mothers' socialization of gratitude did not significantly predict the total number of gratitude examples given by children. However, the role of children’s gender was apparent in the full model, indicating a gender difference for the total number of gratitude examples provided. Specifically, female children provided significantly more examples of what they were grateful for as compared to male children. This is in line with research that shows adolescent girls report more gratitude than boys at the trend level (Froh et al., 2009) and that men are less likely to feel and express gratitude (Kashdan, Mishra, Breen, \& Froh, 2009). Furthermore, research regarding gratitude experience in adults suggests that men may interpret feelings of gratitude as indebtedness and as a threat to their masculinity and social standing (Kashdan et al., 2009). Thus, males may be less likely to provide examples of gratitude when asked to describe what they are grateful for and conceal their gratitude instead of expressing it to others (Kashdan et al., 2009). However, one study indicates that adolescent boys may gain more social benefits from gratitude (Froh et al., 2009). Specifically, the association between gratitude and family support was moderated by gender, whereby boys who reported higher levels of gratitude also reported receiving higher levels of support from family members. These findings may potentially be due to the fact that parents engage in less socialization of emotions in general 
with their sons as compared to their daughters (Froh et al., 2009) and thus, boys benefit socially more from experiencing gratitude as compared to emotional socialization. This supports the hypothesis of the current study that although gratitude socialization is important, it is through the mechanism of gratitude experience and expression that children benefit from gratitude.

Finally, mothers' socialization of gratitude marginally predicted children's number of advanced gratitude examples. However, the full model was marginally significant due to the impact of children's age on the number of examples provided. Though age only marginally predicted differences in the number of examples provided, this correlational trend revealed that older children provided more examples of higher-order/advanced gratitude (e.g., god, shelter, feeling fortunate). This finding, although marginally significant, falls in line with previous research (Gordon et al., 2004) and the hypotheses of the current study that older children have a better understanding of gratitude.

Several indices of maternal socialization of gratitude did not emerge as significant predictors of children's gratitude. Specifically, maternal socialization measures tapping into modeling (PEARS-A) and maternal responses to children's gratitude and positive events (PRCPE) were not associated with any indicators of children's gratitude. Perhaps it is the combination of socialization methods that is most effective in helping children understand gratitude. The global code for the current study represents emotion discussion, but may be tapping into additional socialization behaviors such as modeling and responding to children's own expressions/examples of gratitude. This theory is supported by research that suggests emotion coaching is one of the most effective and powerful tools to cultivate emotional understanding in individuals (Gottman et al., 1996; Gus et al., 2015). Emotion coaching includes an awareness and acceptance of emotions, the discussion of emotions, the validation of feeling 
emotions, and labeling emotions (Gus et al., 2015). Additionally, asking children to discuss how their parents show gratitude and examine if their responses are consistent with the way that parents report they show gratitude would be beneficial. Moreover, observational studies in natural settings would be useful in order to better tap into modeling appreciative behavior.

\section{Mothers’ Gratitude, Children’s Gratitude, and Outcomes}

Concerning the second hypothesis of the current study, results were similarly inconsistent with prior research findings. Multiple regression analyses were conducted to examine whether children's gratitude predicted associations in the four child outcome variables (depressive symptoms, communication skills, problem behaviors, and positive affect). Regarding depressive symptoms, there were no significant predictors of depressive symptoms in children in terms of children's understanding and frequency of gratitude. However, there were both gender and age differences in levels of depressive symptoms reported by children. Furthermore, when examining problem behaviors results showed that although there were no significant predictors of problem behaviors, there was an age difference in levels of problem behaviors reported by mothers.

Regarding positive affect as the outcome, findings showed that there were no significant predictors of positive affect in children. In the current study, mothers' report of how often their children actually felt positive affect over a course of a week was used to represent well-being of children. It is important to note that children’s actual positive affect was reported by mothers. Perhaps children should self-report on their own levels of positive affect in future studies incase parent-report of this variable is not entirely accurate. Research shows that children (especially boys) may not be entirely forthcoming with feelings of sadness or negativity (Chaplin et al., 2005) and thus, parents may overestimate the levels of positive affect their children feel or express. Accurate assessments of children’s well-being are imperative as gratitude has been 
shown in numerous studies to increase subjective well-being for children and adolescents (Emmons \& McCullough 2003; Froh et al., 2009b; Froh et al., 2014; McCullough et al., 2004; Tian et al., 2014; Wang et al., 2015; Wood et al., 2010). For instance, in one study where children were randomly assigned to either a control group or a gratitude group (involving teaching children about gratitude through an awareness of benefit appraisals), the results indicated the gratitude group increased levels of grateful mood, subjective well-being, and lifesatisfaction (Froh et al., 2014). Additionally, increased levels of gratitude have been also shown to predict domain-specific (school) well-being in children (Tian et al., 2014). Nonetheless, most of the literature assessing the link between gratitude and well-being focused on adult samples and thus, more studies including children and adolescents is necessary.

In terms of overall social skills and communication skills specifically (communication is one of the subscales of the overall social skills score for children), children's understanding of gratitude (global code) significantly predicted higher levels of both social skills and communication skills in children. Precisely, children who better understood gratitude also had better social skills overall (communication specifically). These findings are consistent with literature stating that higher levels of gratitude expression and experience are associated with better social skills and increased prosocial behavior in children (Bono et al., 2009). However, considering only communication skills emerged as a significant outcome in this mediation analysis, it is important to note that directionality is unclear regarding this outcome variable. Specifically, it is unclear whether children initially had great communication skills to that lead them to engage in more discussions about gratitude or if an increased understanding of gratitude as a result of discussing the construct led to better mother-reported communication skills. 
Additional research studies with longitudinal designs are necessary to tease apart directionality regarding gratitude socialization and child outcomes.

Although not a main hypothesis of the current study, it is important to discuss several indices of maternal socialization that were not associated with child outcomes. Mothers’ definition of gratitude and number of total and higher-order gratitude examples were not associated with child outcomes. These codes were created to tap into mothers' socialization of gratitude, but because these codes were not typical examples of emotion socialization behaviors

they may not directly relate to child outcomes. In contrast, mothers' own gratitude (PEARS-A) and mothers' encouragement of gratitude (PRCPE) were positively associated with children's social skills overall, potentially due to shared method variance (all mother-report surveys). Moreover, mother’s own gratitude (PEARS-A) was positively associated with children’s communication and negatively associated with children’s problem behaviors. Again, this may partly be due to shared method variance. However, these findings are consistent with literature that shows maternal encouragement of positive emotions lead to fewer externalizing behaviors for children with lower self-control (Yi, Gentzler, Ramsey, \& Root, 2015) and proactive parenting predicted fewer problem behaviors over time for children (Denham et al., 2000). Nevertheless, future studies should account for reporter biases and utilize independent sources for all key study variables.

\section{Putting It All Together: Mediation Analyses and Age as a Moderator}

Prior research in the field of gratitude has been restricted to examining the expression and experience of gratitude as it relates to outcomes in predominantly adult samples. Previous research has largely overlooked the significance of parental socialization of gratitude. Thus, the current study investigated if parental socialization of gratitude is associated with child outcomes 
(well-being, depressive symptoms, and social skills) through children's gratitude. This study also tested a plausible developmental hypothesis that the previously mentioned model would be stronger for older kids, as older children may have more time to be socialized and also be able to understand gratitude at a more advanced level.

One significant mediation model emerged, perhaps the most salient finding of the current study. Specifically, results indicated that mothers' elaboration of gratitude during the discussion significantly predicted children's understanding of gratitude, and that children's understanding of gratitude significantly predicted children’s communication skills. Furthermore, mothers’ elaboration of gratitude significantly predicted children's communication skills, but dropped to non-significant after controlling for children’s understanding of gratitude. This finding implies that parental socialization of gratitude is not necessarily effective if the child doesn't understand what gratitude means to its full extent (shown by the positive association between children's understanding of gratitude and communication). Furthermore, in the only study currently known to examine parental socialization methods for gratitude, researchers focused on niche-selection as a possible strategy (Rothenberg et al., 2017). In their study, results indicated that the link between parental socialization and child outcomes could partially be explained by providing opportunities for children to express gratitude (niche-selection). However, Rothenberg and colleagues also believe that there are additional mediators/factors at play that can explain this association. This idea is in line with the hypothesis of the current study that the association between mothers' socialization and child outcomes is mediated by children's gratitude. It is also important to address that communication; a subscale of the general social skills measure was the only outcome variable that emerged in the mediation model. This is an important finding because gratitude is strongly linked to social skills and strengthening relationships between individuals. 
Gratitude has been shown to strengthen bonds (often examined with romantic partners) through the social exchange process between benefactor and beneficiary (Algoe, 2012). Specially, the find-remind-and-bind theory postulates that gratitude expression helps individuals find new or remind them of existing partners to bind to and promotes positive appraisals of these relationships (Algoe, 2012). This theory has long term implications because stronger social skills early in childhood (e.g., communication) transfer to relationships in adulthood (Algoe, 2012; Algoe \& Haidt, 2009; Algoe, Haidt, \& Gable, 2008; Bartlett \& DeSteno, 2016).

Only one moderated mediation model was significant in the direction hypothesized for the current study. Specifically, it was found that mothers' elaboration of gratitude (during the discussion task) was significantly positively associated with children's communication skills (mother-report) through the mechanism of children's understanding of gratitude (during the discussion task). Moreover, the positive association between children's understanding of gratitude and their communication skills was significant for older children only (path b). However, the positive association between mother's elaboration of socialization and children's understanding of gratitude was not moderated by child's age (path a). This finding is consistent with research on socialization of emotions with preschoolers, whereby parental intensity of emotion expressiveness predicted emotion understanding even when controlling for age and cognitive ability in children (Denham et al., 1994). Perhaps the degree to which mothers teach their children about gratitude is equally beneficial for children of all ages. However, it is possible that older children engage in more acts of gratitude and it is not simply the understanding of gratitude or the number of examples of gratitude provided that matters, but the active experience of engaging in grateful acts/frequency of gratitude that leads to an increase in communication. Regarding age, in one study examining gratitude examples provided by children and adolescents 
(ages 7 to 14), findings revealed that younger children were more likely to give examples of verbal gratitude (e.g., saying thank you), whereas older children gave more examples of connective gratitude, the most sophisticated type of gratitude (e.g., express gratitude for the wellbeing of others; Wang et al., 2015). Furthermore, studies investigating the efficacy of gratitude interventions suggest that expressions of gratitude such as actively counting your blessings for two weeks predicts increased reports of school satisfaction and subjective well-being for adolescents in sixth and seventh grade (Froh et al., 2008). Taking into account past research and the findings of the current study, more research is necessary to accurately map out the developmental trajectory of gratitude in individuals.

\section{Strengths, Limitations, and Future Directions}

Although the current study is not without its limitations, the weaknesses of this study provide an opportunity for new research to address these issues and continue to provide relevant findings in the field of positive psychology. The current study is one of the first to examine parental socialization of gratitude and thus serves as a starting point for future research. It is important to note though that the data utilized for analysis was part of a larger study examining positive emotions in children. This study contained both quantitative and qualitative measures, which was a strength of the study. The current study has important implications regarding qualitative data concerning how mothers and children think about and discuss gratitude together. Future studies can benefit from creating new coding schemes to tap into additional aspects of gratitude in addition to socialization methods. For example, continuing to explore the facial expressions associated with gratitude experience and expression, how gratitude feels, and teasing apart emotional, cognitive, and behavioral aspects of gratitude would be beneficial. The current study created coding schemes to examine how gratitude looks and feels like and these data 
provide a wealth of qualitative data that future researchers can work with. In the future, children and parents can be asked to explicitly explain why they might be grateful for the other person. In light of this, the current study has some weaknesses that are worth mentioning.

The sample size for the current study was adequate according to G*Power calculations. However, a larger sample would be beneficial in future studies to increase power to detect potential significant associations that may have been missed in the current study due to low power (evidenced by the low effect sizes for significant findings). A larger sample size may help researchers examine moderated effects between mothers’ socialization variables. Perhaps mother's own gratitude predicts well-being in children, but only for those who also encourage their children to be grateful. Similarly, mother's likelihood to encourage gratitude with their children (survey data) may predict social skills in children, but is moderated by mother's elaboration of gratitude (discussion task). Overall, the sample for the current study was largely middle class, educated, White individuals, so a more heterogeneous sample is recommended to examine possible cultural differences in the socialization, experience, and expression of gratitude. This lack of diversity is important to note because research suggests there are cultural differences in the way that gratitude is expressed and felt. For example, Wang and colleagues found that children in collectivistic cultures like China expressed significantly more connective gratitude (most sophisticated type of gratitude) than individuals in the United States (Wang et al., 2015). Additionally, people in individualistic cultures such as the United States are known to more commonly display positive emotions like pride as opposed to collectivistic cultures (Tsai, Miao, Seppala, Fung, \& Yeung, 2007). Nonetheless, as children age, they expressed more connective gratitude regardless of culture (Wang et al., 2015), suggesting a developmental trajectory for gratitude. 
Furthermore, because gratitude helps individuals see things in a better light (Lambert et al., 2012), and that a major component of the emotion is to be content with what you have (i.e., grateful), variations in socio-demographic profiles may differentially influence the extent to which parents find gratitude an important emotion to socialize with their children. In the current study, household income was not associated with main study variables. However, mothers’ education and religious importance were linked to mothers' socialization of gratitude. This is in line with a study using an adult sample showing a clear link between religiosity and gratitude (Krause, 2006). It is interesting to note though that dispositional gratitude better predicted wellbeing in undergraduate students as compared to religious gratitude specifically (i.e., gratitude towards a higher-power; Aghababaei \& Tabik, 2013). Additionally, considering the number of children within the household is important because differences exist in the way that parents socialize their children based on factors such as temperament and the gender of the child. Consequently, siblings may be socialized differently by their parents. Specifically, research shows that parents may socialize their children differently based on their temperament, starting as early as infancy by responding more frequently to babies with an easy temperament (Chess \& Thomas, 1996). In childhood, parents continue to socialize their sons and daughters in an inconsistent manner, promoting emotions that are in line with societal expectations regarding cultural norms for emotion expression (Brody, 2000).

Finally, the inclusion of father-child dyads would be advantageous. In a two-parent household it is inevitable that each parent takes a role in the socialization of emotions so examining the differences between how mothers and fathers teach their kids about gratitude is important as it could provide valuable information on how parents differentially affect child outcomes. The current study analyzed data with mothers only, however, research on emotion 
socialization in general indicates that fathers differentially socialize their children based on gender, more accepting of girl's submissive emotions than boys (Chaplin et al., 2005). Furthermore, research suggests fathers are more likely to engage in gender-specific socialization as compared to mothers (Chaplin et al., 2005) by encouraging their sons more than daughters to control their emotions and to stop crying (Eisenberg et al., 1998). Similarly, fathers are more likely to discuss emotions with their daughters than sons, but boys and men in general discuss emotions less than girls and women do so this must be taken into consideration as well (Eisenberg et al., 1998; Chaplin et al., 2005) especially in a one-parent household consisting of fathers only. These parental differences in socialization methods are important to note because parents may socialize emotions differently based on common gender differences in emotion expression of their children (e.g., girls express more sadness than boys and boys express more anger than girls; Brody, 2000). Moreover, research shows that examining both maternal and paternal socialization of prosocial development is important as mothers and fathers use different methods to teach their children about emotions (e.g., fathers are more agentic and instrumental, whereas mothers are more communal; Hastings, Miller, \& Troxel, 2015). Thus, parents may be socializing prosocial development with their children based on gender norms regarding helping behavior. This is consistent with literature that states boys and girls may express prosocial behaviors in different ways, with girls more likely to engage in helping behaviors and scoring higher on measures of empathy and nurture, while boys engage in helping behaviors that are more heroic or chivalrous (Hastings et al., 2015). If gratitude socialization follows a similar trend, the current study measures may not be tapping into ways that boys are taught to express gratitude. Thus, more research is recommended to explore how parent socialization techniques differentially influence children based on gender. 
In addition to issues with the sample, there were potential limitations in the current study with measures potentially not tapping into the socialization of gratitude specifically. Perhaps some of the example events don't evoke feelings of gratitude as easily as other events might. For example, asking mothers how likely they are to encourage their child to be grateful for “receiving a surprise gift from grandma” may be a more appropriate example as opposed to a positive event from the PRCPE measure such as "your child earned an A on their exam”. There is a possibility that parents are less likely to think of gratitude when their child earns an A on an exam versus their child receiving a gift from grandma. Furthermore, including validated measures of gratitude such as the Gratitude Questionnaire-6 (McCullough et al., 2002) or the Gratitude Resentment and Appreciation Test (Thomas \& Watkins, 2003) would be useful to examine levels of dispositional gratitude in participants and whether these measures generalize to children as well. It is important to keep in mind though, that it is difficult to know what constitutes the most appropriate measure for these aspects of gratitude as there is limited research on the socialization of gratitude in children and no current measures known to the author exist that examine children’s understanding of gratitude.

Much of the initial literature investigating gratitude and children involved the use of correlational data and cross-sectional study designs (Emmons \& McCullough, 2004), whereas research today has shifted to explore alternative study designs (e.g., experimental). For example, Froh and colleagues randomly assigned early adolescents ( $6^{\text {th }}$ and $7^{\text {th }}$ graders) into three different groups (control, hassles, and gratitude) and found that children in the gratitude group reported significantly higher levels of life satisfaction, optimism, and less negative affect after counting blessings in their lives in comparison to the other treatment groups (Froh et al., 2008). This finding suggests a causal nature for gratitude, but additional empirical work encompassing a 
range of age groups (e.g., middle childhood) is necessary to extend this research. Additionally, more longitudinal studies are needed to examine the developmental trajectory of gratitude. Furthermore, it would be beneficial to start research with children as early as possible, especially around 3 to 4 as this age represents the time when children begin to develop theory of mind (Layous \& Lyubomirsky, 2014). An earlier start to research can aid psychologists in pinpointing when gratitude can first be fully understood by children and map out the unique way that gratitude understanding progresses as individuals grow.

Another avenue to explore is the reasons why parents socialize gratitude with their children. Research shows that depending on who the socialization agent is, the goals of that individual may vary. Moreover, parental goals regarding emotion expression may vary as a result of differing emotion norms (e.g., gender roles based on femininity and masculinity of emotions) across cultures (Brody, 2000; Eisenberg et al., 1998.) However, most researchers agree that a common goal among parents is to increase the emotional competence of their children (e.g., expressing and regulating emotions in a socially acceptable way). Thus, the motivation or intent behind parental socialization of gratitude could hopefully help determine which socialization methods are better for certain goals. A possible reason parent's might socialize gratitude in their children is to follow social norms and teach children to display good manners in the community. Additionally, parents may see the socialization of gratitude as a social responsibility to promote social justice. Specifically, parents may perceive gratitude as a moral virtue and believe that cultivating gratitude not only helps the self, but society as a whole (Froh et al., 2009; Wang et al., 2015). However, some parents may believe that expressing gratitude goes beyond good manners and saying thank you when appropriate. Instead, some parents may conceptualize gratitude as a deeper understanding and appreciation for what you have and understanding that 
you don't need to have everything that others do-it's being content with exactly what you have in life (Gordon et al., 2004; Halberstadt et al., 2016).

In addition to examining the reasons why parents socialize gratitude, it is equally important to assess some of the reasons given for why individuals should feel and express gratitude. As previously stated, there are a multitude of benefits associated with both gratitude experience and expression; an increase in well-being, increased social skills, and less depressive symptoms (Froh et al., 2008; Nelson \& Lyubomirsky, 2014). Furthermore, being grateful can alter your perspective on life--help you see a negative situation in a better light (Lambert et al., 2012). Positive emotions have the ability to broaden and build individuals' thought-action repertoire for positive emotions (Fredrickson, 2001). Specifically, increased gratitude experience may lead to novel ways of thinking and behaving that ultimately lead to new and useful resources. For example, broaden and build may help individuals build close relationships that help foster new coping skills that ultimately help reduce depressive symptoms. Alternatively, parents may encourage different aspects of gratitude (e.g., cognitive or emotional components) depending on their reason for socializing this emotion and thus, broaden and build may look different across families and cultures. Perhaps religious reasons to socialize gratitude fosters social interaction and closeness in the form of group prayer and counting blessings whereas socialization of gratitude to follow social norms is displayed through actions of respect at the dinner table or giving thanks for Christmas presents. Moreover, gratitude also promotes forgiveness (Breen, Kashdan, Lenser, \& Fincham, 2010) and strengthens relationships (Algoe et al., 2010; Algoe et al., 2013). Additional reasons people might want to feel or express gratitude include social norms and religion. Specifically, social convention (values of the family household/rules of etiquette) may be a driving force of gratitude expression along with 
obligations or commandments of a religious belief (Aghababaei \& Tabik, 2013). However, not all reasons for gratitude experience or expression align with the definition of gratitude presented by the current study. Specifically, many researchers agree that the expression of gratitude solely for prudential reasons (to benefit yourself) is not actually an act of "genuine” gratitude (McCullough et al., 2004), even though in some instances the same expressions of gratitude may be seen for different gratitude socialization goals. Consequently, more research is essential to better understand the many facets of gratitude and how the reasons for gratitude socialization are linked to expressions of gratitude considering individual and cultural differences. These differences may pinpoint certain aspects of gratitude interventions that may be tailored to specific families, and cultures.

Because examining the socialization of gratitude in children is novel, considering the larger relational system of socialization and additional outcome variables may also be beneficial. Specifically, researchers should explore whether the socialization of gratitude is a distinct process or whether it overlaps with other constructs such as parental warmth or attachment, and the role of attachment security as a predictor of gratitude (Dwiwardani et al., 2014). This is vital to consider because parent's role in these constructs also serves to promote kindness and helping behaviors in children (Gross, Stern, Brett, \& Cassidy, 2017). Perhaps examining these broader constructs in future studies could explain null findings by illuminating other factors at play not captured by the current study (e.g., prosocial behaviors). Moreover, this may help researchers develop appropriate measures to assess gratitude and potential outcomes in children. This is important to note because studies report that both elementary students (Tian et al., 2015) and college students (Bartlett \& DeSteno, 2006; McCullough et al., 2002) with higher levels of 
gratitude also report engaging in higher levels of prosocial behaviors. Thus, additional outcome variables such as prosocial development should be examined in future studies.

Future studies would also benefit from examining how socialization variables for gratitude may interact to differentially influence child outcomes. It is possible certain indices of maternal socialization of gratitude predict child outcomes, but only for mothers who are also higher in warmth. Alternatively, mother's own gratitude (tapping into modeling) may predict child outcomes, but only for mothers who also reported higher levels of other indices of gratitude socialization such as mothers ‘encouragement of gratitude or mothers' accurate definitions of gratitude. Furthermore, the social interaction between children and their parents may change depending on the domain in which socialization occurs (Grusec \& Davidov, 2015). Within the reciprocity domain of socialization, parents and their children interact in situations where reciprocity is encouraged and cultivated (i.e., sharing toys and joy during play time), whereas the protection domain encourages socialization in situations that involve threat, which may not foster acts of gratitude as easily or may foster different examples of gratitude expression (Grusec \& Davidov, 2015). For example, the protection domain may result in perspective taking and feeling fortunate as others may be experiencing more serious threatening situations. Thus, tapping into domain-specific socialization (the reciprocity domain specifically) is recommended in future studies to examine situations appropriate for gratitude expression and experience.

The current study focused on identifying effective socialization methods parents can utilize to teach their children about gratitude. However, "effective” socialization is not defined within the gratitude literature. Individual differences based on culture or personal beliefs might exists regarding the way that effective socialization is conceptualized by parents. Effective socialization may be defined by the successful achievement of aims set forth by parents for their 
children. Although we know that the socialization of emotions is important for helping children gain the skills to effectively regulate their emotions (Denham, 1997; Rothenberg et al., 2017), the aims of socialization may still differ across cultures and different groups of people. Considering these findings in combination with the implications of the current study, multiple mechanisms may be at play in connecting parent gratitude and child outcomes. The current study suggests this link is due to children's gratitude, and not only the understanding of gratitude, but the frequency and expression of children's gratitude that may specifically connect these variables.

Consequently, research examining gratitude socialization and the cultivation of gratitude as early as childhood is imperative. The current study serves as a starting point for examining potential methods of gratitude socialization that could provide evidence for "effective" socialization of gratitude in the future.

In conclusion, the current study offers new insights into the methods of emotion socialization that may be appropriate for helping children better understand the construct of gratitude. The findings of the current study highlight the significance of not only maternal socialization of gratitude, but the important role children's understanding and frequency of gratitude plays in the association between children's gratitude and positive outcomes. Thus, the results of the study have implications for not only parents, but for the continued implementation of gratitude interventions in schools. This is important, because research shows gratitude interventions such as the "gratitude visit” intervention or writing 'thank you' letters are advantageous for children as they increase levels of subjective well-being, quality of peer friendships, and academic achievement (Bono \& Froh, 2009). These interventions should be implemented early in youth because research shows not only children benefit greatly from gratitude, but future benefactors involved in the social exchange process of gratitude, indicating 
that a cycle of gratitude exists to enhance multiple lives at one time (Froh et al., 2009a). Because the current study is novel in nature, future studies that continue to examine the socialization of gratitude in children can help move science forward. 


\section{References}

Aghababaei, N., \& Tabik, M. T. (2013). Gratitude and mental health: Differences between religious and general gratitude in a Muslim context. Mental Health, Religion \& Culture, 16(8), 761-766.

Algoe, S. B. (2012). Find, remind, and bind: The functions of gratitude in everyday relationships. Social and Personality Psychology Compass, 6(6), 455-469. doi: 10.1111/j.1751-9004.2012.00439.x

Algoe, S. B., Fredrickson, B. L., \& Gable, S. L. (2013). The social functions of the emotion of gratitude via expression. Emotion, 13(4), 605-9. http://doi.org/10.1037/a0032701

Algoe, S. B., Haidt, J., \& Gable, S. L. (2008). Beyond reciprocity: Gratitude and relationships in everyday life. Emotion, 8(3), 425-9. http://doi.org/10.1037/1528-3542.8.3.425

Baker, J. K., Fenning, R. M., \& Crnic, K. A. (2011). Emotion socialization by mothers and fathers: Coherence among behaviors and associations with parent attitudes and children's social competence. Social Development, 20(2), 412-430. http://doi.org/10.1111/j.1467$\underline{9507.2010 .00585 . \mathrm{x}}$

Bamford, C., \& Lagattuta, K. H. (2012). Looking on the bright side: Children’s knowledge about the benefits of positive versus negative thinking. Child development, 83(2), 667-682.

Bandura, A. (1977). Social learning theory. Englewood Cliffs, NJ: Prentice Hall.

Bartlett, L., \& DeSteno, D. (2006). Gratitude and prosocial behavior. Psychological Science, 17(4), 319-325. http://doi.org/10.1111/j.1467-9280.2006.01705.x

Bird, J. M., \& Markle, R. S. (2012). Subjective well-being in school environments: Promoting positive youth development through evidence-based assessment and intervention. 
American Journal of Orthopsychiatry, 82(1), 61-66. http://doi.org/10.1111/j.1939$\underline{0025.2011 .01127 . \mathrm{x}}$

Bono, G., \& Froh, J. (2009). Gratitude in school: Benefits to students and schools. In R. Gilman, E. S. Huebner, \& M. J. Furlong (Eds.), Handbook of positive psychology in schools (pp. 77-88). New York: Routledge/Taylor \& Francis Group.

Bono, G., Froh, J. J., \& Forrett, R. (2014). Gratitude in school: Benefits to students and schools. In M. J. Furlong, R. Gilman, E. S. Huebner, M. J. Furlong, R. Gilman, E. S. Huebner (Eds.) Handbook of positive psychology in schools (2nd ed.) (pp. 67-81). New York, NY, US: Routledge/Taylor \& Francis Group.

Breen, W. E., Kashdan, T. B., Lenser, M. L., \& Fincham, F. D. (2010). Gratitude and forgiveness: Convergence and divergence on self-report and informant ratings. Personality and Individual Differences, 49(8), 932-937. https://doi.org/10.1016/j.paid.2010.07.033

Brody, L. R. (2000). The socialization of gender differences in emotional expression: Display rules, infant temperament, and differentiation. In A. H. Fischer (Ed.), Gender and emotion: Social psychological perspectives (pp. 24-47). Cambridge, UK: Cambridge University Press.

Chaplin, T. M., Cole, P. M., \& Zahn-Waxler, C. (2005). Parental socialization of emotion expression: Gender differences and relations to child adjustment. Emotion 5(1), 80-88. http://doi.org/10.1037/1528-3542.5.1.80

Chess, S., \& Thomas, A. (1996). Temperament: Theory and Practice (Brunner/Mazel basic principles into practice series, v. 12). New York: Brunner/Mazel. 
Denham, S. (1997). Parental contributions to preschoolers’ emotional competence: Direct and indirect effects. Motivation and Emotion, 21, 65-86.

Denham, S. A. (1998). The Guilford series on Special and emotional development. Emotional development in young children. New York: Guilford Press.

Denham, S. A., Caal, S., Bassett, H. H., Benga, O., \& Geangu, E. (2004). Listening to parents: Cultural variations in the meaning of emotions and emotion socialization. Cognitive Brain Behavior, 8, 321-350.

Denham, S. A., Workman, E., Cole, P. M., Weissbrod, C., Kendziora, K. T., \& Zahn-Waxler, C. (2000). Prediction of externalizing behavior problems from early to middle childhood: The role of parental socialization and emotion expression. Development and Psychopathology, 12(1), 23-45. doi:10.1017/S0954579400001024

Denham, S. A., Zoller, D., \& Couchoud, E. A. (1994). Socialization of preschoolers’ emotion understanding. Developmental Psychology, 30(6), 928-936. https://doi.org/10.1037/0012$\underline{1649.30 .6 .928}$

Dwiwardani, C., Hill, P. C., Bollinger, R. A., Marks, L. E., Steele, J. A., Doolin, H. N., ... \& Davis, D. E. (2014). Virtues develop from a secure base: Attachment and resilience as predictors of humility, gratitude, and forgiveness. Journal of Psychology \& Theology, 42(1). 83-90.

Eisenberg, N., Cumberland, A., \& Spinrad, T. L. (1998). Parental socialization of emotion. Psychological Inquiry, 9(4), 241-273.

Eisenberg, N., Fabes, R. A., Shepard, S. A., Guthrie, I. K., Murphy, B. C., \& Reiser, M. (1999). Parental reactions to children’s negative emotions: Longitudinal relations to quality of children’s social functioning. Child Development, 70, 513-534. 
Emmons, R. A., \& McCullough, M. E. (2003). Counting blessings versus burdens: An experimental investigation of gratitude and subjective well-being in daily life. Journal of Personality and Social Psychology, 84(2), 377-389. http://doi.org/10.1037/0022-

\section{$\underline{3514.84 .2 .377}$}

Emmons, R. A., \& McCullough, M. E. (Eds.). (2004). The psychology of gratitude. Oxford University Press.

Emmons, R. A., \& Mishra, A. (2012). Why gratitude enhances well-being: What we know, what we need to know. In Sheldon, K., Kashdan, T., \& Steger, M.F. (Eds.) Designing the future of positive psychology: Taking stock and moving forward. New York: Oxford University Press.

Erdfelder, E., Faul, F., \& Buchner, A. (1996). GPOWER: A general power analysis program. Behavior Research Methods, Instruments, \& Computers, 28(1), 1-11.

Fabes, R. A., Poulin, R. E., Eisenberg, N., \& Madden-Derdich, D. A. (2002). The Coping with Children's Negative Emotions Scale (CCNES): Psychometric properties and relations with children's emotional competence. Marriage \& Family Review, 34(3-4), 285-310. doi:10.1300/J002v34n03_05

Faul, F., Erdfelder, E., Lang, A. G., \& Buchner, A. (2007). G*Power 3: A flexible statistical power analysis program for the social, behavioral, and biomedical sciences. Behavior Research Methods, 39, 175-191.

Faulstich, M. E., Carey, M. P., Ruggiero, L., Enyart, P., \& Gresham, F. (1986). Assessment of depression in childhood and adolescence: An evaluation of the Center for Epidemiological Studies Depression Scale for Children (CES-DC). The American Journal of Psychiatry, 143(8), 1024-1027. 
Fredrickson, B. L. (1998). What good are positive emotions? Review of General Psychology, 2(3), 300-319. doi.org/10.1037/1089-2680.2.3.300

Fredrickson, B. L. (2001). The role of positive emotions in positive psychology: The broadenand-build theory of positive emotions. American Psychologist, 56(3), 218-226.

Froh, J. J., \& Bono, G. (2008). The gratitude of youth. In S. J. Lopez (Ed.) Positive psychology: Exploring the best in people (Vol. 2, pp. 55-78). Westport, CT: Greenwood Press

Froh, J. J., Bono, G., \& Emmons, R. A. (2010). Being grateful is beyond good manners: Gratitude and motivation to contribute to society among early adolescents. Motivation and Emotion, 34(2), 144-157.

Froh, J. J., Bono, G., Fan, J., Emmons, R. A., Henderson, K., Harris, C. ... Wood, A. M. (2014). Nice thinking! An educational intervention that teaches children to think gratefully. School Psychology Review, 43(2), 132-152.

Froh, J. J., Emmons, R. A., Card, N. A., Bono, G., \& Wilson, J. (2011a). Gratitude and the reduced costs of materialism in adolescents. Journal of Happiness Studies, 12, 289-302.

Froh, J. J., Fan, J., Emmons, R. A., Bono, G., Huebner, E. S., \& Watkins, P. (2011b). Measuring gratitude in youth: Assessing the psychometric properties of adult gratitude scales in children and adolescents. Psychological Assessment, 23(2), 311-324. http://doi.org/10.1037/a0021590

Froh, J. J., Kashdan, T. B., Ozimkowski, K. M., \& Miller, N. (2009a). Who benefits the most from a gratitude intervention in children and adolescents? Examining positive affect as a moderator. The Journal of Positive Psychology, 4(5), 408-422. doi:10.1080/17439760902992464 
Froh, J. J., Miller, D. N., \& Snyder, S. F. (2007). School Psychology Forum. School Psychology Forum, 2(1), 1-13.

Froh, J. J., Yurkewicz, C., \& Kashdan, T. B. (2009b). Gratitude and subjective well-being in early adolescence: Examining gender differences. Journal of Adolescence, 32(3), 633650. http://doi.org/10.1016/j.adolescence.2008.06.006

Gentzler, A. L., \& Palmer, C. (2014). Positive Events and Responses Survey for Youth. Unpublished measure.

Gentzler, A. L., \& Ramsey, M. A. (2014). Parents’ Responses to Children’s Positive Events. Unpublished measure.

Gentzler, A. L., Ramsey, M. A., \& Black, K. R. (2015). Mothers’ attachment styles and their children's self-reported security, as related to maternal socialization of children's positive affect regulation. Attachment \& Human Development, 17(4), 376-398. http://doi.org/10.1080/14616734.2015.1055507

Gleason, J. B., \& Weintraub, S. (1976). The acquisition of routines in child language. Language in Society, 5(2), 129-136.

Gordon, A. K., Musher-Eizenman, D. R., Holub, S. C., \& Dalrymple, J. (2004). What are children thankful for? An archival analysis of gratitude before and after the attacks of September 11. Journal of Applied Developmental Psychology, 25(5), 541-553. https://doi.org/10.1016/j.appdev.2004.08.004

Gottman, J. M., Katz, L. F., \& Hooven, C. (1996). Parental meta-emotion philosophy and the emotional life of families: Theoretical models and preliminary data. Journal of Family Psychology, 10(3), 243-268. http://doi.org/10.1037/0893-3200.10.3.243 
Graham, S., \& Weiner, B. (1986). From an attributional theory of emotion to developmental psychology: A round-trip ticket? Social Cognition, 4(2), 152-179.

Grant, A. M., \& Gino, F. (2010). A little thanks goes a long way: Explaining why gratitude expressions motivate prosocial behavior. Journal of Personality and Social Psychology, 98(6), 946-955. http://doi.org/10.1037/a0017935

Gross, J. J., \& Levenson, R. W. (1997). Hiding feelings: The acute effects of inhibiting negative and positive emotion. Journal of Abnormal Psychology, 106(1), 95-103.

Gross, J. J., \& Muñoz, R. F. (1995). Emotion regulation and mental health. Clinical Psychology: Science and Practice, 2(2), 151-164.

Gross, J. T., Stern, J. A., Brett, B. E., \& Cassidy, J. (2017). The multifaceted nature of prosocial behavior in children: Links with attachment theory and research. Social Development, 26(4), 661-678.

Grusec, J. E., \& Davidov, M. (2015). Analyzing Socialization from a Domain-Specific Perspective. In Handbook of Socialization: Theory and Research (2nd ed., pp. 158-181). New York, NY: The Guilford Press.

Gus, L., Rose, J., \& Gilbert, L. (2015). Emotion Coaching: A universal strategy for supporting and promoting sustainable emotional and behavioural well-being. Educational \& Child Psychology, 32(1), 31-41.

Gresham, F., \& Elliott, S. N. (2007). Social Skills Improvement System (SSIS) Rating Scales. San Antonio, TX: Pearson Education Inc.

Halberstadt, A. G., Langley, H. A., Hussong, A. M., Rothenberg, W. A., Coffman, J. L., Mokrova, I., \& Costanzo, P. R. (2016). Parents' understanding of gratitude in children: A 
thematic analysis. Early Childhood Research Quarterly, 36, 439-451. http://doi.org/10.1016/j.ecresq.2016.01.014

Hastings, P. D., Miller, J. G., \& Troxel, N. R. (2015). Making Good: The Socialization of Children’s Prosocial Development. In Handbook of Socialization: Theory and Research (2nd ed., pp. 637-660). New York, NY: The Guilford Press.

Hayes, A. F. (2012). PROCESS: A versatile computational tool for observed variable mediation, moderation, and conditional process modeling.

Hubbard, J. A., \& Coie, J. D. (1994). Emotional correlates of social competence in children's peer relationships. Merrill-Palmer Quarterly (1982-), 1-20.

Jones, S., Eisenberg, N., Fabes, R. A., \& MacKinnon, D. P. (2002). Parents' reactions to elementary school children's negative emotions: Relations to social and emotional functioning at school. Merrill-Palmer Quarterly, 48(2), 133-159.

doi:10.1353/mpq.2002.0007

Kashdan, T. B., Mishra, A., Breen, W. E., \& Froh, J. J. (2009). Gender differences in gratitude: Examining appraisals, narratives, the willingness to express emotions, and changes in psychological needs. Journal of Personality, 77(3), 691-730. https://doi.org/10.1111/j.1467-6494.2009.00562.x

Katz, L. F., \& Hunter, E. C. (2007). Maternal meta-emotion philosophy and adolescent depressive symptomatology. Social Development, 16, 343-360.

Katz, L. F., Shortt, J. W., Allen, N. B., Davis, B., Hunter, E., Leve, C., \& Sheeber, L. (2014). Parental emotion socialization in clinically depressed adolescents: Enhancing and dampening positive affect. Journal of Abnormal Child Psychology, 42(2), 205-215. http://doi.org/10.1007/s10802-013-9784-2 
Kennedy Root, A., \& Denham, S. A. (2010). The role of gender in the socialization of emotion: Key concepts and critical issues. In A. Kennedy Root \& S. Denham (Eds.), The role of gender in the socialization of emotion: Key concepts and critical issues. New Directions for Child and Adolescent Development, 128, 1-9. San Francisco: Jossey-Bass.

Klimes-Dougan, B., Brand, A. E., Zahn-Waxler, C., Usher, B., Hastings, P. D., Kendziora, K., \& Garside, R. B. (2007). Parental emotion socialization in adolescence: Differences in sex, age and problem status. Social Development, 16(2), 326-342. http://doi.org/10.1111/j.1467-9507.2007.00387.x

Kong, F., Ding, K., \& Zhao, J. (2015). The relationships among gratitude, self-esteem, social support and life satisfaction among undergraduate students. Journal of Happiness Studies, 16(2), 477-489. http://doi.org/10.1007/s10902-014-9519-2

Krause, N. (2006). Gratitude toward god, stress, and health in late life. Research on Aging, 28(2), 163-183. https://doi.org/10.1177/0164027505284048

Lambert, N. M., Fincham, F. D., \& Stillman, T. F. (2012). Gratitude and depressive symptoms: The role of positive reframing and positive emotion. Cognition \& Emotion, 26(4), 615633. http://doi.org/10.1080/02699931.2011.595393

Layous, K., \& Lyubomirsky, S. (2014). Benefits, mechanisms, and new directions for teaching gratitude to children. School Psychology Review, 43(2), 153-159.

McCullough, M. E., Emmons, R. A., \& Tsang, J. A. (2002). The grateful disposition: A conceptual and empirical topography. Journal of Personality and Social Psychology, 82(1), 112-127. http://doi.org/10.1037//0022-3514.82.1.112

McCullough, M. E., Tsang, J. A., \& Emmons, R. A. (2004). Gratitude in intermediate affective terrain: Links of grateful moods to individual differences and daily emotional experience. 
Journal of Personality and Social Psychology, 86(2), 295-309.

http://doi.org/10.1037/0022-3514.86.2.295

McElwain, N. L., Halberstadt, A. G., \& Volling, B. L. (2007). Mother- and father-reported reactions to children's negative emotions: Relations to young children's emotional understanding and friendship quality. Child Development, 78, 1407-1425.

Morris, A. S., Silk, J. S., Steinberg, L., Myers, S. S., \& Robinson, L. R. (2007). The role of the family context in the development of emotion regulation. Social development, 16(2), 361388. http://doi.org/10.1111/j.1467-9507.2007.00389.x.

Nelson, S. K. \& Lyubomirsky, S. (2014). Finding happiness: Tailoring positive activities for optimal well-being benefits. In M. Tugade, M. Shiota, \& L. Kirby (Eds.), Handbook of positive emotions. New York: Guilford.

Owens, R. L., \& Patterson, M. M. (2013). Positive psychological interventions for children: A comparison of gratitude and best possible selves approaches. Journal of Genetic Psychology, 174(4), 403-428. http://doi.org/10.1080/00221325.2012.697496

Park, N., Peterson, C., \& Seligman, M. E. (2004). Strengths of character and well-being. Journal of Social and Clinical Psychology, 23(5), 603-619.

Poelker, K. E., \& Kuebli, J. E. (2014). Does the thought count? Gratitude understanding in elementary school students. The Journal of genetic psychology, 175(5), 431-448. http://doi.org/10.1080/00221325.2014.941321

Ramsden, S. R., \& Hubbard, J. A. (2002). Family expressiveness and parental emotion coaching: Their role in children's emotion regulation and aggression. Journal of Abnormal Child Psychology, 30(6), 657-667. http://doi.org/10.1023/A:1020819915881 
Ramsey, M. A., \& Gentzler, A. L. (2014). Age differences in subjective well-being across adulthood: The roles of savoring and future time perspective. The International Journal of Aging and Human Development, 78(1), 3-22. doi:10.2190/AG.78.1.b

Roberts, R. C. (2004). The Blessings of Gratitude: A Conceptual Analysis. In R. A. Emmons \& M. E. McCullough (Eds.), Series in affective science. The psychology of gratitude (pp. 58-78).

Root, A. K. and Rubin, K. H. (2010). Gender and parents' reactions to children's emotion during the preschool years. New Directions for Child and Adolescent Development, 51-64. doi:10.1002/cd.268

Rothenberg, W. A., Hussong, A. M., Langley, H. A., Egerton, G. A., Halberstadt, A. G., Coffman, J. L., ... \& Costanzo, P. R. (2017). Grateful parents raising grateful children: Niche selection and the socialization of child gratitude. Applied Developmental Science, 21(2), 106-120.

Ruch, W., Weber, M., Park, N., \& Peterson, C. (2014). Character strengths in children and adolescents: Reliability and initial validity of the German values in action inventory of strengths for youth (German VIA-Youth). European Journal of Psychological Assessment, 30(1), 57-64. http://doi.org/10.1027/1015-5759/a000169

Seligman, M. E. P., \& Csikszentmihalyi, M. (2000). Positive psychology: An introduction. American Psychologist, 55(1), 5-14. http://doi.org/10.1037//0003-066X.55.1.5

Seligman, M. E. P., Steen, T. A, Park, N., \& Peterson, C. (2005). Positive psychology progress: Empirical validation of interventions. The American Psychologist, 60(5), 410-421. http://doi.org/10.1037/0003-066X.60.5.410 
Sheldon, K. M., \& Lyubomirsky, S. (2006). How to increase and sustain positive emotion: The effects of expressing gratitude and visualizing best possible selves. The Journal of Positive Psychology, 1(2), 73-82.

Stocker, C. M., Richmond, M. K., Rhoades, G. K., \& Kiang, L. (2007). Family emotional processes and adolescents’ adjustment. Social Development, 16(2), 310-325. http://doi.org/10.1111/j.1467-9507.2007.00386.x

Thomas, N. \& Watkins, P. (2003). Measuring the Grateful Trait: Development of the Revised GRAT. Poster presented to the Annual Convention of the Western Psychological Association, May, 2003, Vancouver, BC.

Tian, L., Du, M., \& Huebner, E. S. (2015). The effect of gratitude on elementary school students’ subjective well-being in schools: the mediating role of prosocial behavior. Social Indicators Research, 122(3), 887-904. http://doi.org/10.1007/s11205-014-0712-9

Tsai, J.L. Knutson, B., \& Fung, H. H. (2006). Cultural variation in affect valuation. Journal of Personality and Social Psychology, 90, 288-307.

Tsai, J. L., Miao, F. F., Seppala, E., Fung, H. H., \& Yeung, D. Y. (2007). Influence and adjustment goals: Sources of cultural differences in ideal affect. Journal of Personality and Social Psychology, 92(6), 1102-1113.

Wang, D., Wang, Y. C., \& Tudge, J. R. (2015). Expressions of gratitude in children and adolescents insights from China and the United States. Journal of Cross-Cultural Psychology, 46(8), 1039-1058. http://doi.org/10.1177/0022022115594140

Weissman, M. M., Orvaschel, H., Padian N. (1980). Children’s symptom and social functioning self-report scales: Comparison of mothers’ and children’s reports. Journal of Nervous Mental Disorders, 168(12), 736-740. 
Wood, A. M., Froh, J. J., \& Geraghty, A. W. (2010). Gratitude and well-being: A review and theoretical integration. Clinical Psychology Review, 30(7), 890-905.

Wood, A. M., Joseph, S., \& Maltby, J. (2008a). Gratitude uniquely predicts satisfaction with life: Incremental validity above the domains and facets of the five factor model. Personality and Individual Differences, 45, 49-54.

Wood, A. M., Maltby, J., Gillett, R., Linley, P. A., \& Joseph, S. (2008b). The role of gratitude in the development of social support, stress, and depression: Two longitudinal studies. Journal of Research in Personality, 42, 854-871.

Yap, M. B. H., Allen, N. B., \& Ladouceur, C. D. (2008). Maternal socialization of positive affect: The impact of invalidation on adolescent emotion regulation and depressive symptomatology. Child Development, 79(5), 1415-1431. http://doi.org/10.1111/j.14678624.2008.01196.x

Yi, C. Y., Gentzler, A. L., Ramsey, M. A., \& Root, A. E. (2016). Linking maternal socialization of positive emotions to children's behavioral problems: The moderating role of selfcontrol. Journal of Child and Family Studies, 25(5), 1550-1558.

https://doi.org/10.1007/s10826-015-0329-X

Zahn-Waxler, C. (2010). Socialization of emotion: Who influences whom and how? New directions for child and adolescent development, 2010(128), 101-109. 
Table 1

Descriptive Statistics for Mom and Child Demographic Information

\begin{tabular}{|c|c|c|c|}
\hline Variables & & Frequency (\%) & Mean (SD) \\
\hline \multirow[t]{2}{*}{ Child Gender } & Female & $44(45.4)$ & $1.55(.50)$ \\
\hline & Male & $53(54.6)$ & \\
\hline \multirow[t]{2}{*}{ Child Age } & Younger (ages 7 to 9) & 63 (64.9) & $8.79(1.41)$ \\
\hline & Older (ages 10 to 12 ) & $34(35.1)$ & \\
\hline \multirow{6}{*}{$\begin{array}{l}\text { Mother } \\
\text { Marital Status }\end{array}$} & Married, living with & 76 (80.9) & 1.51 (1.09) \\
\hline & partner & & \\
\hline & $\begin{array}{l}\text { Married, but } \\
\text { separated }\end{array}$ & $2(2.1)$ & \\
\hline & Not married, but & $2(2.1)$ & \\
\hline & living with partner & & \\
\hline & $\begin{array}{l}\text { Not married, and not } \\
\text { living with partner }\end{array}$ & $14(14.9)$ & \\
\hline \multirow[t]{4}{*}{ Income } & Up to $\$ 39,999$ & $19(19.4)$ & 7.98 (3.13) \\
\hline & $\$ 40,000$ to $\$ 79,999$ & $29(30.2)$ & \\
\hline & $\$ 80,000$ to $\$ 149,999$ & $40(43.0)$ & \\
\hline & Over $\$ 150,000$ & $7(7.5)$ & \\
\hline \multirow[t]{4}{*}{ Education } & $\begin{array}{l}11^{\text {th }} \text { grade completed } \\
\text { to } 3 \text { years of college }\end{array}$ & 25 (25.5) & $10.09(2.16)$ \\
\hline & $\begin{array}{l}\text { Graduate from 4-year } \\
\text { college to some grad. } \\
\text { school }\end{array}$ & $39(41.5)$ & \\
\hline & $\begin{array}{l}\text { Master's degree or 2- } \\
\text { 3-year grad program }\end{array}$ & 19 (19.1) & \\
\hline & M.D. or Ph.D. & $13(13.8)$ & \\
\hline \multirow[t]{2}{*}{ Mom Ethnicity } & White & $88(90.7)$ & $.09(.29)$ \\
\hline & Other & $9(9.3)$ & \\
\hline \multirow[t]{4}{*}{ Religion } & Catholic & $20(23.5)$ & $2.58(2.31)$ \\
\hline & Protestant & $54(63.5)$ & \\
\hline & Agnostic & $8(9.4)$ & \\
\hline & Other & $3(3.6)$ & \\
\hline \multirow{4}{*}{$\begin{array}{l}\text { Religious } \\
\text { Importance }\end{array}$} & 1 (Not at all)- 2 & $15(16.0)$ & $5.17(2.00)$ \\
\hline & 3-4 (Somewhat) & $18(19.2)$ & \\
\hline & $5-6$ & 27 (27.6) & \\
\hline & 7 (Very Important) & $36(37.2)$ & \\
\hline
\end{tabular}


Table 2

Coding Scheme for Mothers' and Children's Gratitude Definitions and Examples

\begin{tabular}{|c|c|c|c|c|c|c|}
\hline & \multirow{3}{*}{ Definition } & \multirow{3}{*}{ Parent and Child Examples } & \multicolumn{2}{|c|}{ Mothers } & \multicolumn{2}{|c|}{ Children } \\
\hline & & & $\%$ & $\%$ & $\%$ & \\
\hline & & & & & & \\
\hline 1 & Don’t know/wrong answer & $\begin{array}{l}\text { "I don’t know what gratitude means.” } \\
\text { (a child) }\end{array}$ & $1.1 \%$ & $0 \%$ & $49.5 \%$ & $2.1 \%$ \\
\hline 2 & $\begin{array}{l}\text { Good feeling (glad/happy) or } \\
\text { just being thankful/grateful }\end{array}$ & $\begin{array}{l}\text { "It means being thankful and it's a } \\
\text { happy feeling." (a mother) }\end{array}$ & $20 \%$ & $0 \%$ & $20 \%$ & $0 \%$ \\
\hline 3 & Glad/happy for material items & $\begin{array}{l}\text { "I am thankful for my toys, and that I } \\
\text { have my own room." (a child) }\end{array}$ & $25.3 \%$ & $1.1 \%$ & $13.7 \%$ & $17.9 \%$ \\
\hline 4 & $\begin{array}{l}\text { Thankful for specific activities } \\
\text { or things that people do }\end{array}$ & $\begin{array}{l}\text { "I am thankful that we got to go to } \\
\text { Disney World as a family." (a child) }\end{array}$ & $16.8 \%$ & $6.3 \%$ & $4.2 \%$ & $7.4 \%$ \\
\hline 5 & $\begin{array}{l}\text { Thankful for specific people for } \\
\text { unspecified reasons or for love }\end{array}$ & $\begin{array}{l}\text { "I am thankful for my sissy and my } \\
\text { mom and my dad and my teachers." (a } \\
\text { child) }\end{array}$ & $14.7 \%$ & $23.2 \%$ & $6.3 \%$ & $30.5 \%$ \\
\hline 6 & $\begin{array}{l}\text { Thankful for one } \\
\text { advanced/abstract thing }\end{array}$ & $\begin{array}{c}\text { "Being grateful is appreciating what } \\
\text { you have and not wanting more.” (a } \\
\text { mother) }\end{array}$ & $16.8 \%$ & $24.2 \%$ & $3.2 \%$ & $17.9 \%$ \\
\hline \multirow[t]{3}{*}{7} & $\begin{array}{l}\text { Thankful for two or more } \\
\text { advanced/abstract things }\end{array}$ & $\begin{array}{l}\text { "I am thankful for God, and that we } \\
\text { have a house and food to eat." (a child) }\end{array}$ & $5.3 \%$ & $45.3 \%$ & $3.2 \%$ & $24.2 \%$ \\
\hline & & $M(S D)$ & $3.96(1.57)$ & $6.06(1.02)$ & $2.20(1.63)$ & $5.15(1.51)$ \\
\hline & & Kappa & $\begin{array}{c}.86 \\
(N=22)\end{array}$ & $\begin{array}{c}.88 \\
(N=22)\end{array}$ & $\begin{array}{c}.84 \\
(N=16)\end{array}$ & $\begin{array}{c}.83 \\
(N=20)\end{array}$ \\
\hline
\end{tabular}


Table 3

Mothers' and Children's Gratitude Examples

\begin{tabular}{|c|c|c|c|c|c|c|c|}
\hline Category & Category Examples & $\begin{array}{l}\text { Parent and Child } \\
\text { Examples }\end{array}$ & $\begin{array}{l}\text { Parent } \\
M(S D)\end{array}$ & $\begin{array}{l}\text { Parent } \\
\text { Range }\end{array}$ & $\begin{array}{c}\text { Child } \\
M(S D)\end{array}$ & $\begin{array}{l}\text { Child } \\
\text { Range }\end{array}$ & $\begin{array}{l}\text { Reliability } \\
\text { (ICC) }\end{array}$ \\
\hline People & $\begin{array}{l}\text { Family members, relatives, peers, } \\
\text { friends, teachers, heroes and role } \\
\text { models, relationships, people in } \\
\text { general }\end{array}$ & $\begin{array}{l}\text { "Having gratitude is a being } \\
\text { thankful for family, for } \\
\text { nana and papa.” (a mother) }\end{array}$ & $2.06(1.77)$ & $0-8$ & $1.73(1.50)$ & $0-6$ & $.86-.96$ \\
\hline Material Items & Materialistic possessions & $\begin{array}{l}\text { "I am grateful that you } \\
\text { bought me video games." (a } \\
\text { child) }\end{array}$ & $.28(.59)$ & $0-3$ & $.95(1.10)$ & $0-5$ & $.66-.84$ \\
\hline Religion & $\begin{array}{l}\text { Praying, counting your blessings, } \\
\text { going to church, and } \\
\text { religion/spirituality }\end{array}$ & $\begin{array}{l}\text { “We could show gratitude } \\
\text { by praying more.” (a child) }\end{array}$ & $.27(.70)$ & $0-5$ & $.12(.44)$ & $0-3$ & $.75-.84$ \\
\hline $\begin{array}{l}\text { Advanced/Abstract } \\
\text { Things }\end{array}$ & $\begin{array}{l}\text { Basic necessities, shelter, good } \\
\text { health for self or others, safety, } \\
\text { freedom, feeling lucky or fortune, } \\
\text { beauty of natural world, altruism, } \\
\text { personal growth }\end{array}$ & $\begin{array}{l}\text { "I am grateful that I have } \\
\text { healthy kids and smart kids } \\
\text { and that we have a roof } \\
\text { over our heads.” (a mother) } \\
\text { "I think we are lucky for } \\
\text { what we have.” (a child) }\end{array}$ & 3.10 (2.09) & $0-11$ & $2.02(2.02)$ & $0-8$ & $-.05 *-.88$ \\
\hline Total Sources & All of the above & & $5.71(3.11)$ & $0-14$ & $4.78(3.11)$ & $0-15$ & N/A \\
\hline
\end{tabular}

Note. *Low ICC is due to a very small $\mathrm{N}$ for a particular example category. 
Table 4

Correlations between key study variables and participant socio-demographic variables

\begin{tabular}{|c|c|c|c|c|}
\hline Variables & $\begin{array}{c}\text { Mother } \\
\text { Age }\end{array}$ & $\begin{array}{c}\text { Mother } \\
\text { Education }\end{array}$ & $\begin{array}{l}\text { Household } \\
\text { Income }\end{array}$ & $\begin{array}{c}\text { Religious } \\
\text { Importance }\end{array}$ \\
\hline & $r$ & $r$ & $r$ & $r$ \\
\hline \multicolumn{5}{|c|}{ Child Understanding of Gratitude: Survey Data } \\
\hline $\begin{array}{l}\text { Child own gratitude } \\
\text { (PEARS-Y) }\end{array}$ & -.03 & .08 & .14 & -.05 \\
\hline \multicolumn{5}{|c|}{ Child Understanding of Gratitude: Observation Data } \\
\hline $\begin{array}{l}\text { Examples: total } \\
\text { number }\end{array}$ & .05 & -.09 & -.00 & .11 \\
\hline $\begin{array}{l}\text { Examples: higher } \\
\text { order \# }\end{array}$ & .06 & -.13 & .07 & .16 \\
\hline $\begin{array}{l}\text { Gratitude definition: } \\
\text { Likert }\end{array}$ & -.11 & -.05 & .15 & .07 \\
\hline $\begin{array}{l}\text { Gratitude definition } \\
\text { by examples: Likert }\end{array}$ & -.14 & -.14 & -.12 & .06 \\
\hline $\begin{array}{l}\text { Understanding } \\
\text { Global Code }\end{array}$ & -.04 & -.02 & -.00 & .09 \\
\hline \multicolumn{5}{|c|}{ Mother Socialization: Observation Data } \\
\hline $\begin{array}{l}\text { Gratitude definition: } \\
\text { Likert }\end{array}$ & .03 & .06 & .07 & .10 \\
\hline $\begin{array}{l}\text { Examples: total } \\
\text { number }\end{array}$ & -.08 & .05 & .03 & .08 \\
\hline $\begin{array}{l}\text { Examples: higher } \\
\text { order \# }\end{array}$ & .02 & .14 & -.06 & .15 \\
\hline $\begin{array}{l}\text { Gratitude definition } \\
\text { by examples: Likert }\end{array}$ & .04 & $.21 *$ & .06 & .16 \\
\hline $\begin{array}{l}\text { Elaboration global } \\
\text { code }\end{array}$ & -.04 & $.31 * *$ & .10 & .03 \\
\hline \multicolumn{5}{|c|}{ Mother Socialization: Survey Data } \\
\hline $\begin{array}{l}\text { Mother's own } \\
\text { gratitude (PEARS-A) }\end{array}$ & .10 & .07 & .15 & $.35 * *$ \\
\hline $\begin{array}{l}\text { Mother encourage } \\
\text { child (mother report: } \\
\text { PRCPE-A) }\end{array}$ &.$- .32 * *$ & $.25^{*}$ & -.04 & $.28 * *$ \\
\hline $\begin{array}{l}\text { Mother encourage } \\
\text { child (youth report: } \\
\text { PRCPE-Y) }\end{array}$ & -.14 & -.01 & .06 & .00 \\
\hline
\end{tabular}


Table 5

Correlations between Mediator Variables (Children's Gratitude) and Child Outcomes

\begin{tabular}{l|cccc}
\hline Variables & $\begin{array}{c}\text { Mother } \\
\text { Age }\end{array}$ & $\begin{array}{c}\text { Mother } \\
\text { Education }\end{array}$ & $\begin{array}{c}\text { Household } \\
\text { Income }\end{array}$ & $\begin{array}{c}\text { Religious } \\
\text { Importance }\end{array}$ \\
\hline \multicolumn{1}{l}{ Depressive Symptoms } & $r$ & $r$ & $r$ & $r$ \\
Positive Affect & $\underline{-.30^{* *}}$ & -.05 & -.14 & -.06 \\
Social Skills Total & .02 & .11 & .08 & .17 \\
Communication & -.17 & .15 & $\underline{.24^{*}}$ & .01 \\
Problem Behaviors & -.12 & .15 & $\underline{.22^{*}}$ & .00 \\
\hline \multicolumn{2}{l}{ Note. $* p<.05 . * * p<.01}$. & -.19 & $\underline{-.23^{*}}$ & .06 \\
\hline
\end{tabular}


Table 6

Correlations between IVs (Mom Socialization)

\begin{tabular}{|c|c|c|c|c|c|c|c|c|}
\hline Variables & 1. & 2. & 3. & 4. & 5. & 6. & 7. & 8. \\
\hline & $r$ & $r$ & $r$ & $r$ & $r$ & $r$ & $r$ & $r$ \\
\hline \multicolumn{9}{|c|}{ Mother Socialization: Observation Data } \\
\hline $\begin{array}{l}\text { 1. Gratitude definition: } \\
\text { Likert }\end{array}$ & -- & -.02 & -.03 & .18 & -.03 & -.02 & -.04 & .08 \\
\hline $\begin{array}{l}\text { 2. Examples: total } \\
\text { number }\end{array}$ & & -- & $.74 * *$ & $.47^{* *}$ & -.01 & .16 & .06 & .18 \\
\hline $\begin{array}{l}\text { 3. Examples: higher } \\
\text { order \# }\end{array}$ & & & -- &. $.60 * *$ & -.04 & .15 & .07 & .16 \\
\hline $\begin{array}{l}\text { 4. Gratitude definition } \\
\text { by examples: Likert }\end{array}$ & & & & -- & .09 & .12 & .02 & .12 \\
\hline $\begin{array}{l}\text { 5. Elaboration global } \\
\text { code }\end{array}$ & & & & & -- & .16 & .13 & -.09 \\
\hline \multicolumn{9}{|c|}{ Mother Socialization: Survey Data } \\
\hline $\begin{array}{l}\text { 6. Mother own } \\
\text { gratitude (PEARS-A) }\end{array}$ & & & & & & -- & $.35 * *$ & .08 \\
\hline $\begin{array}{l}\text { 7. Mother encourage } \\
\text { child (mother report: } \\
\text { PRCPE-A) }\end{array}$ & & & & & & & -- & .18 \\
\hline $\begin{array}{l}\text { 8. Mother encourage } \\
\text { child (youth report: } \\
\text { PRCPE-Y) }\end{array}$ & & & & & & & & -- \\
\hline Note. ${ }^{*} p<.05 .{ }^{* *} p<$ & & & & & & & & \\
\hline
\end{tabular}


Table 7

Correlations between Mediators (Children's Gratitude)

\begin{tabular}{|c|c|c|c|c|c|c|}
\hline Variables & 1. & 2. & 3. & 4. & 5. & 6. \\
\hline & $r$ & $r$ & $r$ & $r$ & $r$ & $r$ \\
\hline \multicolumn{7}{|c|}{ Child Understanding of Gratitude: Observation Data } \\
\hline $\begin{array}{l}\text { 1. Examples: total } \\
\text { number }\end{array}$ & -- & $.74 * *$ & .08 & $.42 * *$ & $.37 * *$ & -.05 \\
\hline $\begin{array}{l}\text { 2. Examples: higher } \\
\text { order \# }\end{array}$ & & -- & .09 & $.52 * *$ & $.32 * *$ & -.12 \\
\hline $\begin{array}{l}\text { 3. Gratitude definition: } \\
\text { Likert }\end{array}$ & & & -- & $.27 *$ & $.36 * *$ & .08 \\
\hline $\begin{array}{l}\text { 4. Gratitude definition } \\
\text { by examples: Likert }\end{array}$ & & & & -- & $.37 * *$ & -.03 \\
\hline $\begin{array}{l}\text { 5. Understanding } \\
\text { Global Code }\end{array}$ & & & & & -- & -.01 \\
\hline \multicolumn{7}{|c|}{ Child Understanding of Gratitude: Survey Data } \\
\hline $\begin{array}{l}\text { 6. Child own gratitude } \\
\text { (PEARS-Y) }\end{array}$ & & & & & & -- \\
\hline
\end{tabular}


Table 8

Correlations between Child Outcome Variables

\begin{tabular}{l|ccccc}
\hline \multicolumn{1}{l|}{ Variables } & $\mathbf{1 .}$ & $\mathbf{2 .}$ & $\mathbf{3 .}$ & $\mathbf{4 .}$ & $\mathbf{5 .}$ \\
\hline \multicolumn{1}{l}{} & $r$ & $r$ & $r$ & $r$ & $r$ \\
\hline 1. Depressive Symptoms & -- & .14 & .14 & .02 & .12 \\
2. Positive Affect & & -- & $\underline{.34 * *}$ & .15 & -.08 \\
3. Social Skills & & & -- & -- & $\frac{-.59 * *}{-.47^{* *}}$ \\
4. Communication & & & & -- & $\frac{--}{-}$ \\
5. Problem Behaviors & & & & &
\end{tabular}

Note. ${ }^{*} p<.05 .{ }^{* *} p<.01$. Communication is a subscale of Social Skills and thus, their correlation is not reported here. 
Table 9

Correlations between IVs (Mom Socialization) and Mediators (Children's Gratitude)

\begin{tabular}{|c|c|c|c|c|c|c|}
\hline Variables & $\begin{array}{l}\text { Child } \\
\text { report of } \\
\text { gratitude } \\
\text { (PEARS- } \\
\text { Y) }\end{array}$ & $\begin{array}{l}\text { Child } \\
\text { examples } \\
\text { of grat.: } \\
\text { Likert } \\
\text { scale }\end{array}$ & $\begin{array}{l}\text { Child } \\
\text { gratitude } \\
\text { examples: } \\
\text { total } \\
\text { number }\end{array}$ & $\begin{array}{l}\text { Child } \\
\text { gratitude } \\
\text { examples: } \\
\text { higher } \\
\text { order }\end{array}$ & $\begin{array}{l}\text { Child } \\
\text { understanding } \\
\text { global code }\end{array}$ & $\begin{array}{l}\text { Child } \\
\text { definition of } \\
\text { grat.: Likert } \\
\text { scale }\end{array}$ \\
\hline & $r$ & $r$ & $r$ & $r$ & $r$ & $r$ \\
\hline \multicolumn{7}{|c|}{ Mother Socialization: Observation Data } \\
\hline Gratitude definition: Likert & .04 & -.16 & -.14 & -.10 & -.14 & .08 \\
\hline Examples: total number & .04 & $.29 * *$ & $.33 * *$ & $.27 * *$ & .12 & .10 \\
\hline Examples: higher order \# & .02 & $.32 * *$ & $.34 * *$ & $.31 * *$ & .10 & .10 \\
\hline $\begin{array}{l}\text { Gratitude definition by } \\
\text { examples: Likert }\end{array}$ & -.06 & $.25^{*}$ & .16 & .18 & .10 & .00 \\
\hline Elaboration global code & -.06 & .17 & .13 & .19 & $.35 * *$ & .02 \\
\hline \multicolumn{7}{|c|}{ Mother Socialization: Survey Data } \\
\hline $\begin{array}{l}\text { Mother own gratitude } \\
\text { (PEARS-A) }\end{array}$ & .06 & -.04 & .12 & .03 & .04 & .00 \\
\hline $\begin{array}{l}\text { Mother encourage child } \\
\text { (mother report: PRCPE-A) }\end{array}$ & .10 & .13 & -.02 & .09 & .02 & .13 \\
\hline $\begin{array}{l}\text { Mother encourage child } \\
\text { (youth report: PRCPE-Y) }\end{array}$ & $.64 * *$ & .11 & .08 & .12 & -.03 & -.06 \\
\hline$M$ & 3.59 & 5.15 & 5.64 & 2.02 & 2.24 & 2.28 \\
\hline$S D$ & 0.49 & 1.51 & 3.43 & 2.02 & 0.72 & 1.62 \\
\hline Range & $0-4$ & $1-7$ & $0-16$ & $0-7$ & $1-4$ & $1-7$ \\
\hline
\end{tabular}

Note. ${ }^{*} p<.05 .{ }^{* *} p<.01$. PEARS-A = Positive Events and Responses Survey - Adult Report, and PEARS$\mathrm{Y}=$ Positive Events and Responses Survey - Child Report. PRCPE = Parent Responses to Child Positive Events; PRCPE is parent-reported and PRCPE-Y is youth-reported. $N=95$. 
Table 10

Correlations between Mediator Variables (Children's Gratitude) and Child Outcomes

\begin{tabular}{|c|c|c|c|c|c|}
\hline Variables & $\begin{array}{l}\text { Depressive } \\
\text { Symptoms }\end{array}$ & $\begin{array}{l}\text { Positive } \\
\text { Affect }\end{array}$ & $\begin{array}{l}\text { Social Skills } \\
\text { Total }\end{array}$ & Communication & $\begin{array}{l}\text { Problem } \\
\text { Behaviors }\end{array}$ \\
\hline & $r$ & $r$ & $r$ & $r$ & $r$ \\
\hline \multicolumn{6}{|c|}{ Child Understanding of Gratitude: Survey Data } \\
\hline $\begin{array}{l}\text { Child own } \\
\text { gratitude } \\
\text { (PEARS-Y) }\end{array}$ & .07 & .09 & .15 & .06 & -.02 \\
\hline \multicolumn{6}{|c|}{ Child Understanding of Gratitude: Observation Data } \\
\hline $\begin{array}{l}\text { Examples: total } \\
\text { number }\end{array}$ & -.06 & .16 & .01 & .00 & -.12 \\
\hline $\begin{array}{l}\text { Examples: higher } \\
\text { order \# }\end{array}$ & -.11 & .02 & .08 & .07 & -.15 \\
\hline $\begin{array}{l}\text { Gratitude } \\
\text { definition: Likert }\end{array}$ & & & & & \\
\hline $\begin{array}{l}\text { Gratitude } \\
\text { definition by } \\
\text { examples: Likert }\end{array}$ & .02 & .08 & .14 & .10 & -.16 \\
\hline $\begin{array}{l}\text { Understanding } \\
\text { Global Code }\end{array}$ & .04 & .17 & $.23^{*}$ & $.28 * *$ & -.10 \\
\hline$M$ & 3.59 & 5.15 & 96.46 & 16.07 & 2.02 \\
\hline$S D$ & 0.49 & 1.51 & 17.59 & 3.22 & 2.02 \\
\hline Range & $.3-2.2$ & $1.5-4.3$ & $37-132$ & $7-21$ & $3-51$ \\
\hline
\end{tabular}


Table 11

Correlations between IVs (Mom Socialization) and Child Outcomes

\begin{tabular}{|c|c|c|c|c|c|c|c|}
\hline Variables & $\begin{array}{l}\text { Depressive } \\
\text { Symptoms }\end{array}$ & $\begin{array}{l}\text { Positive } \\
\text { Affect }\end{array}$ & $\begin{array}{l}\text { Social } \\
\text { Skills } \\
\text { Total }\end{array}$ & Communication & $\begin{array}{l}\text { Problem } \\
\text { Behaviors }\end{array}$ & $\begin{array}{c}M \\
(S D)\end{array}$ & Range \\
\hline & $r$ & $r$ & $r$ & $r$ & $r$ & $r$ & $r$ \\
\hline \multicolumn{8}{|c|}{ Mother Socialization: Observation Data } \\
\hline $\begin{array}{l}\text { Gratitude } \\
\text { definition: } \\
\text { Likert } \\
\end{array}$ & -.08 & -.07 & .06 & .07 & .05 & $\begin{array}{c}4.02 \\
(1.56)\end{array}$ & $1-7$ \\
\hline $\begin{array}{l}\text { Examples: } \\
\text { total number }\end{array}$ & .06 & .13 & .06 & -.00 & -.07 & $\begin{array}{c}6.69 \\
(3.58)\end{array}$ & $0-16$ \\
\hline $\begin{array}{l}\text { Examples: } \\
\text { higher order \# }\end{array}$ & .02 & .13 & .06 & .02 & -.10 & $\begin{array}{c}3.10 \\
(2.09)\end{array}$ & $0-7$ \\
\hline $\begin{array}{l}\text { Gratitude } \\
\text { definition by } \\
\text { examples: } \\
\text { Likert }\end{array}$ & .01 & .13 & .12 & .09 & -.01 & $\begin{array}{c}6.06 \\
(1.02)\end{array}$ & $3-7$ \\
\hline $\begin{array}{l}\text { Elaboration } \\
\text { global code }\end{array}$ & -.08 & .01 & $.33 * *$ & $.26^{*}$ & $-.33 * *$ & $\begin{array}{l}2.75 \\
(.60)\end{array}$ & $2-4$ \\
\hline \multicolumn{8}{|c|}{ Mother Socialization: Survey Data } \\
\hline $\begin{array}{l}\text { Mother own } \\
\text { gratitude } \\
\text { (PEARS-A) }\end{array}$ & -.09 & .10 & $.38 * *$ & $.23^{*}$ & $\underline{-.34 * *}$ & $\begin{array}{c}4.38 \\
(0.50)\end{array}$ & $1-5$ \\
\hline $\begin{array}{l}\text { Mother } \\
\text { encourage } \\
\text { child (mother } \\
\text { report: } \\
\text { PRCPE-A) } \\
\end{array}$ & .18 & .20 & $.24^{*}$ & .08 & -.13 & $\begin{array}{c}4.17 \\
(0.88)\end{array}$ & $1-5$ \\
\hline $\begin{array}{l}\text { Mother } \\
\text { encourage } \\
\text { child (youth } \\
\text { report: } \\
\text { PRCPE-Y) }\end{array}$ & .10 & .08 & .20 & .08 & -.05 & $\begin{array}{c}3.49 \\
(0.82)\end{array}$ & $1-4$ \\
\hline \multicolumn{8}{|c|}{ Note. ${ }^{*} p<.05 .{ }^{* *} p<.01$} \\
\hline
\end{tabular}


Table 12

Regression Analyses Examining Mom Socialization Variables Predicting Children's Gratitude (Mediator Variables) using Standardized Betas

\begin{tabular}{|c|c|c|c|c|c|c|}
\hline & \multicolumn{6}{|c|}{ Dependent Variables } \\
\hline Variables & $\begin{array}{c}\text { Child } \\
\text { own } \\
\text { gratitude } \\
\text { (PEARS- } \\
\text { Y) } \\
\end{array}$ & $\begin{array}{c}\text { Gratitude } \\
\text { definition } \\
\text { (examples): } \\
\text { Likert }\end{array}$ & $\begin{array}{c}\text { Examples: } \\
\text { total } \\
\text { number }\end{array}$ & $\begin{array}{c}\text { Examples: } \\
\text { higher } \\
\text { order \# }\end{array}$ & $\begin{array}{l}\text { Child } \\
\text { understanding } \\
\text { global code }\end{array}$ & $\begin{array}{l}\text { Gratitude } \\
\text { definition: } \\
\text { Likert } \\
\text { scale }\end{array}$ \\
\hline $\begin{array}{c}\text { Gratitude } \\
\text { definition: } \\
\text { Likert } \\
\end{array}$ & .03 & -.15 & -.10 & -.13 & -.11 & .11 \\
\hline $\begin{array}{l}\text { Examples: } \\
\text { total number }\end{array}$ & -.05 & .20 & $.27+$ & .25 & .06 & .15 \\
\hline $\begin{array}{c}\text { Examples: } \\
\text { higher order } \\
\#\end{array}$ & .04 & -.02 & -.04 & .00 & .06 & .05 \\
\hline $\begin{array}{c}\text { Gratitude } \\
\text { definition } \\
\text { (examples): } \\
\text { Likert }\end{array}$ & -.14 & .19 & .07 & .02 & .05 & -.13 \\
\hline $\begin{array}{l}\text { Elaboration } \\
\text { global code }\end{array}$ & .02 & .08 & -.03 & .04 & $.36 * *$ & .00 \\
\hline $\begin{array}{l}\text { Mother own } \\
\text { gratitude } \\
\text { (PEARS-A) }\end{array}$ & .04 & .06 & .06 & .06 & -.04 & -.11 \\
\hline $\begin{array}{c}\text { Mother } \\
\text { encourage } \\
\text { child } \\
\text { (mother } \\
\text { report: } \\
\text { PRCPE-A) }\end{array}$ & -.03 & .07 & .04 & .05 & -.03 & .15 \\
\hline $\begin{array}{c}\text { Mother } \\
\text { encourage } \\
\text { child (youth } \\
\text { report: } \\
\text { PRCPE-Y) }\end{array}$ & $.67 * *$ & -.07 & .09 & .01 & .01 & -.07 \\
\hline Gender & -.09 & -.14 & $\underline{-.21+}$ & -.05 & -.13 & -.14 \\
\hline Age & -.01 & .06 & -.02 & $.24^{*}$ & .01 & $.22+$ \\
\hline $\begin{array}{l}\text { F-statistic } \\
d f \\
R^{2}\end{array}$ & $\begin{array}{c}6.39 * * * \\
(10,84) \\
.43\end{array}$ & $\begin{array}{c}1.98 * \\
(10,84) \\
.19\end{array}$ & $\begin{array}{c}1.79+ \\
(10,84) \\
.18\end{array}$ & $\begin{array}{c}1.67 \\
(10,84) \\
.07\end{array}$ & $\begin{array}{c}1.77+ \\
(10,84) \\
.17\end{array}$ & $\begin{array}{c}1.20 \\
(10,84) \\
.13\end{array}$ \\
\hline
\end{tabular}


Table 13

Regression Analyses Examining Children's Gratitude Predicting Child Outcomes using Standardized Betas

\begin{tabular}{|c|c|c|c|c|c|}
\hline \multicolumn{6}{|c|}{ Dependent Variables } \\
\hline Variables & $\begin{array}{l}\text { Depressive } \\
\text { Symptoms }\end{array}$ & $\begin{array}{c}\text { Positive } \\
\text { Affect }\end{array}$ & $\begin{array}{l}\text { Social } \\
\text { Skills } \\
\text { Total }\end{array}$ & Communication & $\begin{array}{c}\text { Problem } \\
\text { Behaviors }\end{array}$ \\
\hline $\begin{array}{l}\text { Gratitude } \\
\text { definition: } \\
\text { Likert }\end{array}$ & -.04 & -.11 & -.02 & .05 & .03 \\
\hline $\begin{array}{l}\text { Examples: } \\
\text { total number }\end{array}$ & -.02 & .25 & -.21 & -.20 & -.03 \\
\hline $\begin{array}{l}\text { Examples: } \\
\text { higher order \# }\end{array}$ & -.10 & -.26 & .15 & .12 & -.02 \\
\hline $\begin{array}{l}\text { Gratitude } \\
\text { definition by } \\
\text { examples: } \\
\text { Likert }\end{array}$ & .13 & .05 & .09 & .02 & -.08 \\
\hline $\begin{array}{l}\text { Understanding } \\
\text { Global Code }\end{array}$ & .09 & .16 & $.25^{*}$ & $.30 *$ & -.03 \\
\hline $\begin{array}{l}\text { Child own } \\
\text { gratitude } \\
\text { (PEARS-Y) }\end{array}$ & .06 & .09 & .17 & .06 & -.05 \\
\hline Gender & $.21+$ & -.18 & .03 & .02 & .17 \\
\hline Age & $-.21+$ & .09 & -.04 & -.02 & -.20 \\
\hline F-statistic & 1.46 & 1.40 & 1.24 & 1.22 & 1.14 \\
\hline$d f$ & $(8,86)$ & $(8,86)$ & $(8,86)$ & $(8,86)$ & $(8,86)$ \\
\hline$R^{2}$ & .12 & .12 & .10 & .10 & .10 \\
\hline
\end{tabular}




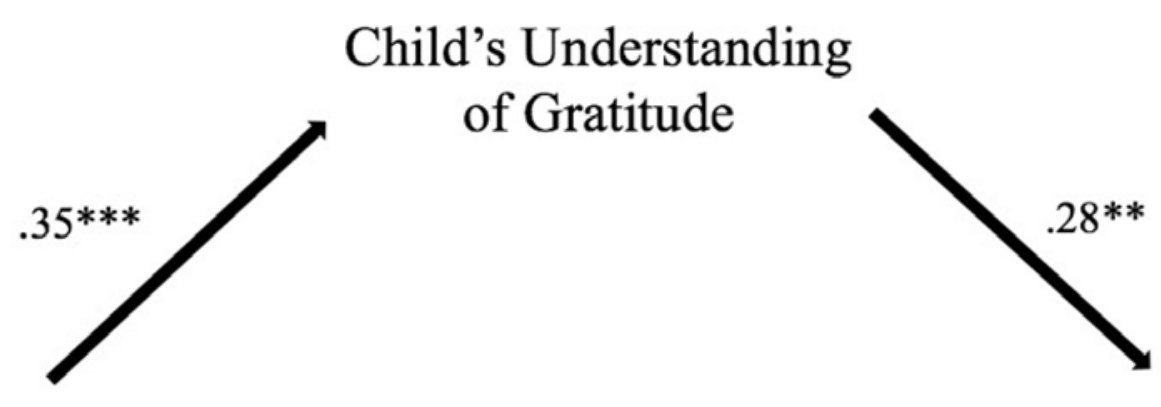

Mother's Elaboration of Gratitude

Direct effect $\mathrm{c}=.26^{* *}$

Indirect effect $=.21 *$

Direct effect $c^{\prime}=.19$

\section{Social Skills : Communication}

Figure 1. Testing the hypothesis that mom's elaboration of gratitude is associated with child communication skills through children's gratitude (presented via standardized beta values).

Note. ${ }^{*} p<.05 . * * p<.01 .{ }^{* * *} p<.001$. 
Appendices 
Appendix A

Mothers’ Socialization of Gratitude \& Children’s Gratitude

\section{DISCUSSION \#2}

We now would like you to have a 5-minute discussion about gratitude.

Please discuss the following 3 points in order:

1) The child should first give his/her opinion on gratitude:

a. What is gratitude? What does it feel like?

b. What makes him/her feel grateful or thankful?

2) The mother should then give her opinion on gratitude:

a. What is gratitude? What does it feel like?

b. What makes her feel grateful or thankful?

3) Together, the mother and child should then discuss whether or not they think they currently feel gratitude enough in their lives, and discuss ways in which they could increase their feelings of gratitude.

After the 5-minutes has ended, the CHILD should indicate how often he/she feels grateful or thankful. Circle one number from 1 to 7 .

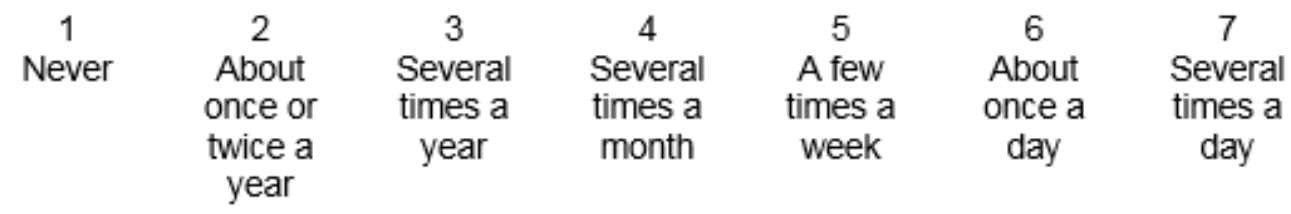

After the 6-minutes has ended, the MOTHER should indicate how often she feels grateful or thankful. Circle one number from 1 to 7 .

\begin{tabular}{|c|c|c|c|c|c|c|}
\hline $\begin{array}{c}1 \\
\text { Never }\end{array}$ & $\begin{array}{c}2 \\
\text { About } \\
\text { once or } \\
\text { twice a }\end{array}$ & $\begin{array}{c}3 \\
\text { Several } \\
\text { times a } \\
\text { year }\end{array}$ & $\begin{array}{c}4 \\
\text { Several } \\
\text { times a } \\
\text { month }\end{array}$ & $\begin{array}{c}5 \\
\text { A few } \\
\text { times a } \\
\text { week }\end{array}$ & $\begin{array}{c}6 \\
\text { About } \\
\text { once a } \\
\text { day }\end{array}$ & $\begin{array}{c}7 \\
\text { Several } \\
\text { times a } \\
\text { day }\end{array}$ \\
\hline
\end{tabular}




\section{Positive Events and Responses Survey for Adults (PEARS-A)}

\section{Positive Events and Responses Survey}

Below are 6 scenarios. Please carefully read them and answer the following questions by clicking on your chosen response. Take a few moments to imagine each situation before proceeding to answer the questions. Even if a scenario has not happened to you personally, please try to imagine it and how, hypothetically, you might respond.

\section{Scenario $\$ 1$}

You tell an important person in your life (e.g. partner/spouse, parent, child, close friend) how much you care about him/her. He/she seems very happy with what you said and says the same thing back in retum.

\section{How happy would you be about this event?}
O Not
$\mathrm{O}_{2}$
$\mathrm{O}_{3}$
$\mathrm{O}_{4}$
$\bigcirc_{\text {Somewhat }}$
$\mathrm{O}_{6} \mathrm{O}_{7} \mathrm{O}_{8}$
○9 $\bigcirc_{\substack{\text { Extremely } \\ \text { happy }}} 10$
happy
happy

\section{How much would you think that this event was in your control (resulting from your} behavior)?

$$
\mathrm{O}_{\text {at all }} \mathrm{Not}_{1} \mathrm{O}_{2} \mathrm{O}_{3} \mathrm{O}_{4} \mathrm{O}_{\substack{\text { Somewhat } \\ \text { in my } \\ \text { control }}} \mathrm{O}_{6} \quad \mathrm{O}_{7} \quad \mathrm{O}^{8} \bigcirc 9 \mathrm{O}_{\substack{\text { Completely } \\ \text { in my } \\ \text { control }}}^{10}
$$

26. How proud would you be about this event?
$\bigcirc_{\text {at all }} 0$ Not $\bigcirc 1$
$\bigcirc_{2} \bigcirc_{3}$
$\mathrm{O}_{4}$
$\mathrm{O}_{5}$
$\mathrm{O}_{6} \mathrm{O}_{7} \mathrm{O}_{8}$
○9 $\bigcirc_{\substack{\text { Extremely } \\ \text { proud }}} 10$ 


\section{How likely would you be to:}

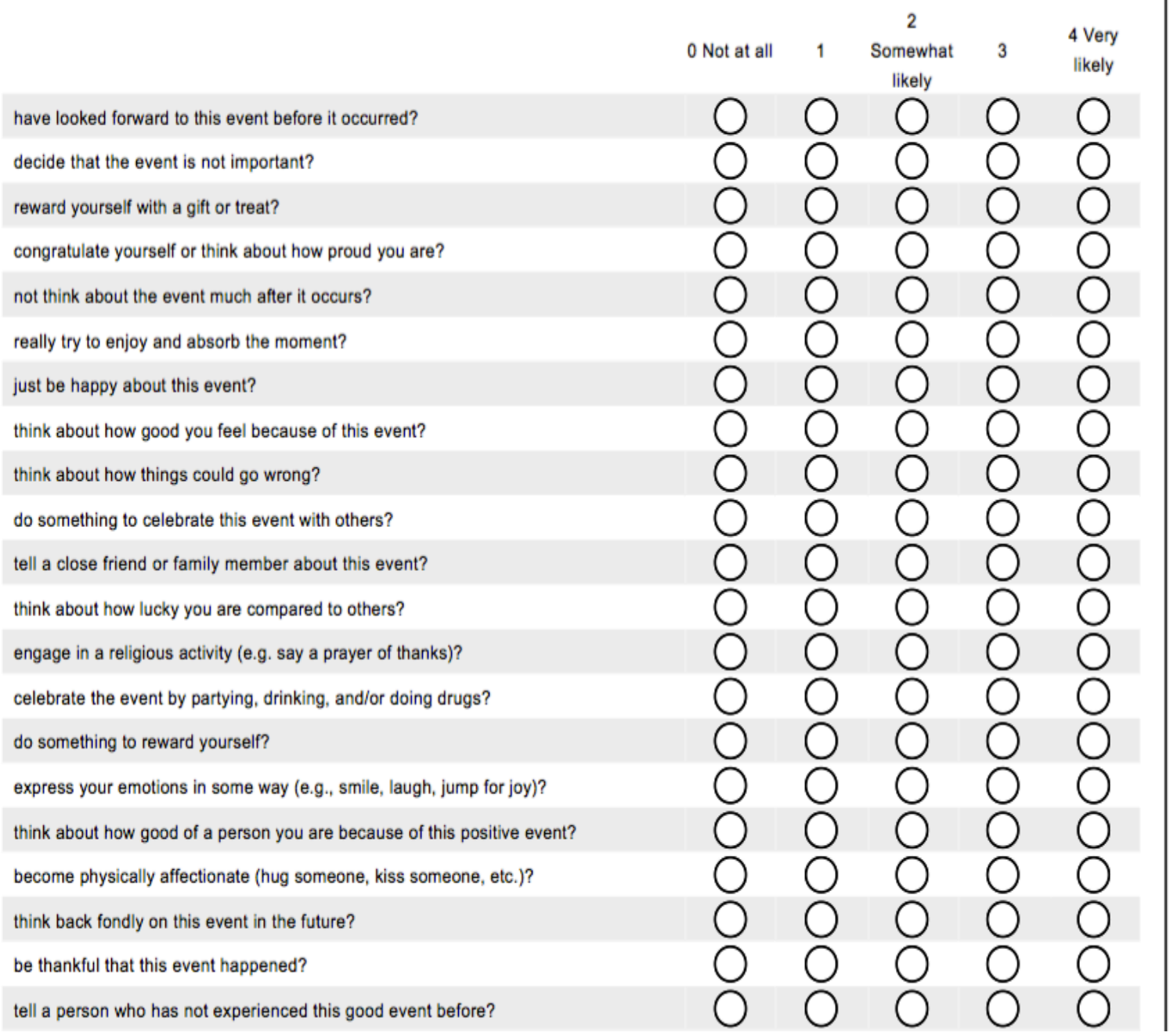




\section{Parents’ Responses to Children's Positive Events (PRCPE)}

\section{Parental Responses to Children's Positive Events (PRCPE)}

Below are 5 hypothetical scenarios that could happen to your child. Please carefully read them and then respond to the following questions. You are first asked to estimate how happy you would be and how proud you would be about the event, and how much the event was in your child's control (0-10 scale). Then answer the remaining questions based on how you think YOU WOULD RESPOND if each event occurred to your child ( $0-4$ scale). Even if the scenario is not something that has happened (or you expect to ever happen) to your child, please try to imagine how you would likely

respond.

\section{Scenario \#1 - Child}

Your child comes home from school and just found out that he/she received an A in his/her most difficult class in school. Your child has been working hard for weeks.

57. How happy would you be about this event?
$\bigcirc 0$
$\bigcirc 1$
$\mathrm{O}_{2} \mathrm{O}_{3}$
$\mathrm{O}_{4}$
$\bigcirc_{5}$ Somewhat happy
$\bigcirc_{6}$
$\mathrm{O}_{7} \mathrm{O}_{8} \quad \mathrm{O}_{9}$
$\bigcirc 10$
Not happy

$$
\text { happy }
$$

58. How proud would you be about this event?
$\bigcirc_{\text {at all }} 0$ Not $\bigcirc 1$
$\mathrm{O}_{2}$
$\bigcirc_{3}$
$\mathrm{O}_{4}$ proud
$\bigcirc_{5}$ Somewhat
$\bigcirc_{6} \bigcirc 7$
$\bigcirc_{8} \bigcirc$ $\bigcirc_{\text {Extremely }} 10$ proud

59. How much would think that your child's grade was in his/her control (resulting from his/her behavior)?<smiles>O[Mg]O[Mg]O</smiles> 


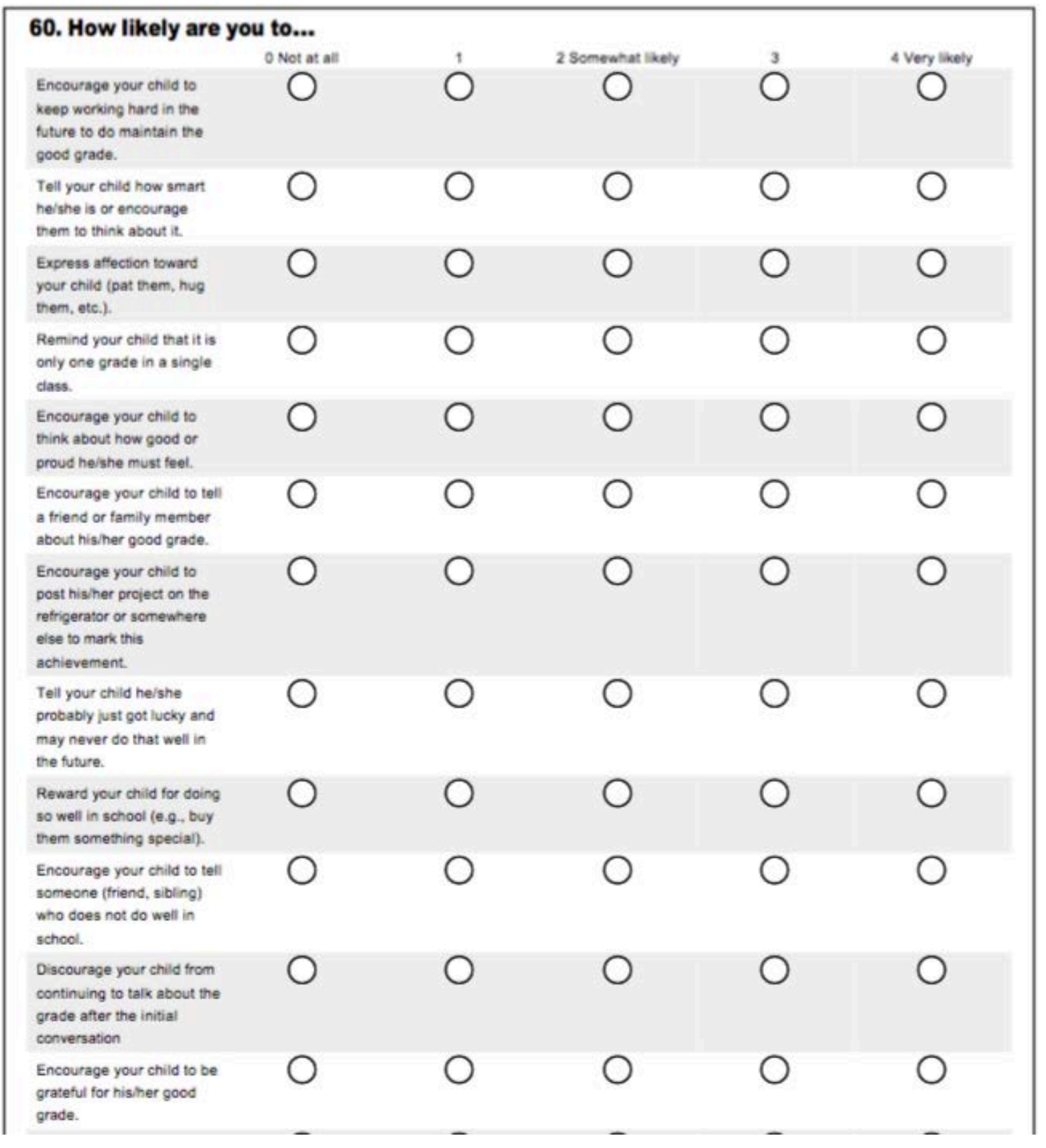




\section{Parents’ Responses to Children’s Positive Events (PRCPE-Y)}

\section{Parental Responses to Children's Positive Events}

Please think about what your MOTHER is like. Specifically, think about how she responds when YOU have a good event happen to YOU, and then answer the following questions. Please carefully read them and circle one answer for each question.

- If you have a good event happen to you and you tell your MOTHER about it, how HAPPY would she be about the event?

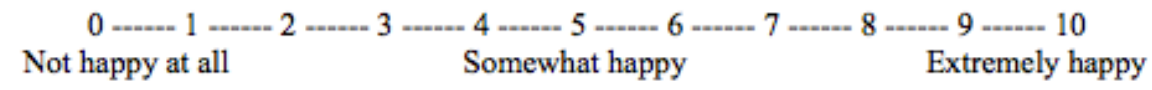

- If you have a good event happen to you and you tell your MOTHER about it, how PPROUD would she be about the event?

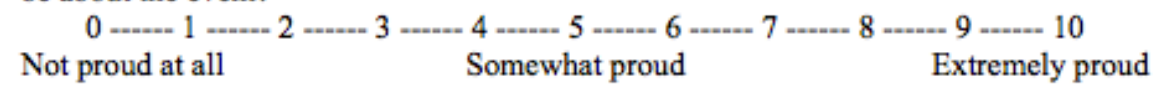

How likely is your MOTHER to...

\begin{tabular}{|c|c|c|c|c|}
\hline $\begin{array}{l}\text { Not } \\
\text { at all }\end{array}$ & & $\begin{array}{l}\text { Some- } \\
\text { what } \\
\text { likely }\end{array}$ & & $\begin{array}{l}\text { Very } \\
\text { Likely }\end{array}$ \\
\hline 0 & 1 & 2 & 3 & 4 \\
\hline 0 & 1 & 2 & 3 & 4 \\
\hline
\end{tabular}

\begin{tabular}{|c|c|c|c|c|}
\hline \multirow[t]{2}{*}{ age you to tell a friend or family member } & 0 & 1 & 2 & 3 \\
\hline & 0 & 1 & 2 & 3 \\
\hline
\end{tabular}
experienced that good event.

\begin{tabular}{|c|c|c|c|c|c|}
\hline help you celebrate, such as take you out to dinner. & 0 & 1 & 2 & 3 & 4 \\
\hline $\begin{array}{l}\text { encourage you to post your accomplishment somewhere or } \\
\text { save a something so that you can remember the good event. }\end{array}$ & 0 & 1 & 2 & 3 & 4 \\
\hline encourage you to think about how good or proud you feel. & 0 & 1 & 2 & 3 & 4 \\
\hline $\begin{array}{l}\text { tell you how smart or talented you are or encourage you to } \\
\text { think about it. }\end{array}$ & 0 & 1 & 2 & 3 & 4 \\
\hline discourage you from continuing to talk about the good event. & 0 & 1 & 2 & 3 & 4 \\
\hline $\begin{array}{l}\text { tell you that you just got lucky and may never do that well in } \\
\text { the future. }\end{array}$ & 0 & 1 & 2 & 3 & 4 \\
\hline $\begin{array}{l}\text { remind you that it is only one event and to not make too much } \\
\text { out of it. }\end{array}$ & 0 & 1 & 2 & 3 & 4 \\
\hline $\begin{array}{l}\text { encourage you to keep doing the same thing in the future so } \\
\text { that you can experience more good events. }\end{array}$ & 0 & 1 & 2 & 3 & 4 \\
\hline $\begin{array}{l}\text { encourage you to express your happiness in some way (smile, } \\
\text { laugh). }\end{array}$ & 0 & 1 & 2 & 3 & 4 \\
\hline express affection toward you (pat you, hug you). & 0 & 1 & 2 & 3 & 4 \\
\hline encourage you to be grateful or thankful for the good event. & 0 & 1 & 2 & 3 & 4 \\
\hline reward you for the good event or for doing so well (buy you & 0 & 1 & 2 & 3 & 4 \\
\hline
\end{tabular}
something special). 


\section{Positive Events and Responses Survey for Youth (PEARS-Y)}

4. You won a contest that gives you a $\$ 100$ gift card to spend at your favorite store. Please circle a number for each question.

- How happy would you be about this event?

$\begin{array}{ll}0 & \\ \text { Not happy at all } & \text { Somewhat happy }\end{array}$

- How proud would you be about this event?

0 Not proud at all
Nomewhat proud

- How much would you think that you caused this event to happen?

$$
\begin{array}{lll}
0 & \\
\text { Not in my control } & \text { Somewhat in my control } & \\
& &
\end{array}
$$

\begin{tabular}{|c|c|c|c|c|c|}
\hline How likely are you to... & $\begin{array}{l}\text { Not } \\
\text { at all }\end{array}$ & & $\begin{array}{c}\text { Some- } \\
\text { what } \\
\text { likely }\end{array}$ & & $\begin{array}{l}\text { Very } \\
\text { Likely }\end{array}$ \\
\hline tell your good friend about your winnings. & 0 & 1 & 2 & 3 & 4 \\
\hline tell a family member about your winnings. & 0 & 1 & 2 & 3 & 4 \\
\hline tell your friend who doesn't have a lot of money to buy things. & 0 & 1 & 2 & 3 & 4 \\
\hline do something to celebrate with family or friends. & 0 & 1 & 2 & 3 & 4 \\
\hline $\begin{array}{l}\text { save the gift card or letter to remind you that you won the } \\
\text { contest, or do something else so you can remember it. }\end{array}$ & 0 & 1 & 2 & 3 & 4 \\
\hline think about how good you feel. & 0 & 1 & 2 & 3 & 4 \\
\hline think about how you deserved to win. & 0 & 1 & 2 & 3 & 4 \\
\hline not think about it much. & 0 & 1 & 2 & 3 & 4 \\
\hline $\begin{array}{l}\text { think that you'll probably spend the gift card in a day so it } \\
\text { won't matter in the long run. }\end{array}$ & 0 & 1 & 2 & 3 & 4 \\
\hline think about how winning the gift card isn't a big deal. & 0 & 1 & 2 & 3 & 4 \\
\hline start entering contests in the future so that you could win again. & 0 & 1 & 2 & 3 & 4 \\
\hline $\begin{array}{l}\text { don't enter a contest again because it seems unlikely that you } \\
\text { could win again. }\end{array}$ & 0 & 1 & 2 & 3 & 4 \\
\hline $\begin{array}{l}\text { do something nice for someone else because you're in such a } \\
\text { good mood. }\end{array}$ & 0 & 1 & 2 & 3 & 4 \\
\hline express your emotions in some way, like smile, laugh, or yell. & 0 & 1 & 2 & 3 & 4 \\
\hline feel grateful or thankful that you won. & 0 & 1 & 2 & 3 & 4 \\
\hline do something to reward yourself (buy something for yourself). & 0 & 1 & 2 & 3 & 4 \\
\hline
\end{tabular}


Appendix B

Child Outcomes Measures

\section{The Center for Epidemiological Studies - Depression Scale Children (CES-DC)}

\section{CES-DC}

ID Number:

Instructions:

Below is a list of the ways you might have felt or acted. Please check how much you have felt this way during the past week.

During the past week

1. I was bothered by things that usually don't bother me.

2. I did not feel like eating, I wasn't very hungry.

3. I wasn't able to feel happy, even when my family or friends tried to help me feel better.

4. I felt like I was just as good as other kids.

5. I felt like I couldn't pay attention to what I was doing.

During the past week

6. I felt down and unhappy.

7. I felt like I was too tired to do things.

8. I felt like something good was going to happen.

9. I felt like things I did before didn't work out right.

10. I felt scared.

During the past week

11. I didn't sleep as well as I usually sleep.

12. I was happy.

13. I was more quiet than usual.

14. I felt lonely, like I didn't have any friends.

15. I felt like kids I know were not friendly or that they didn't want to be with me.

During the past week

16. I had a good time.

17. I felt like crying.

18. I felt sad.

19. I felt people didn't like me.

20. It was hard to get started doing things.
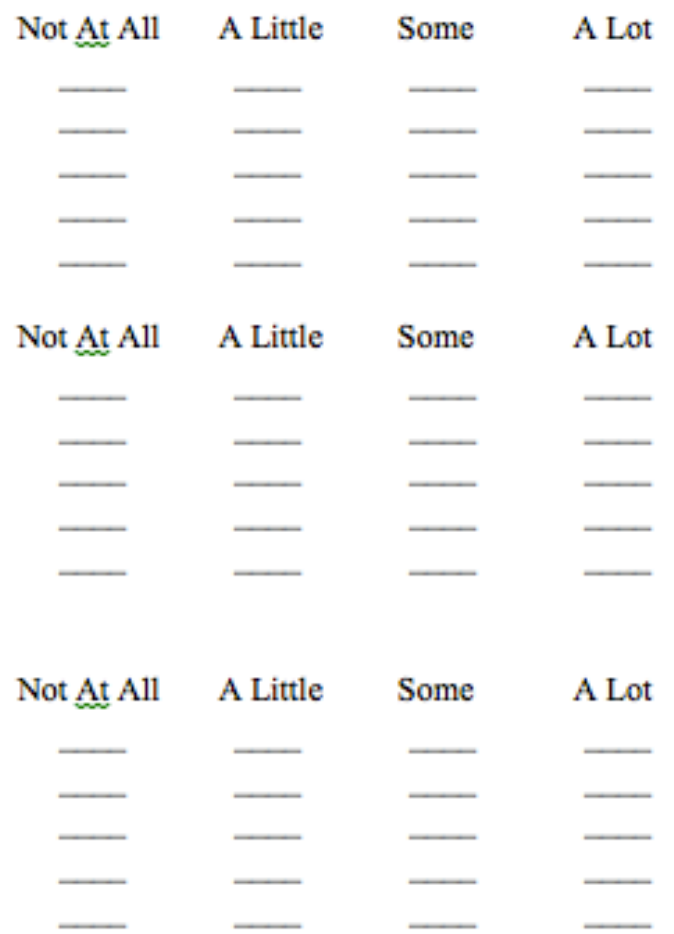
Affect Valuation Index (AVI)

56. Now, please read each word again and rate how often YOUR CHILD ACTUALLY HAS that feeling over the course of a typical week, using the following scale.

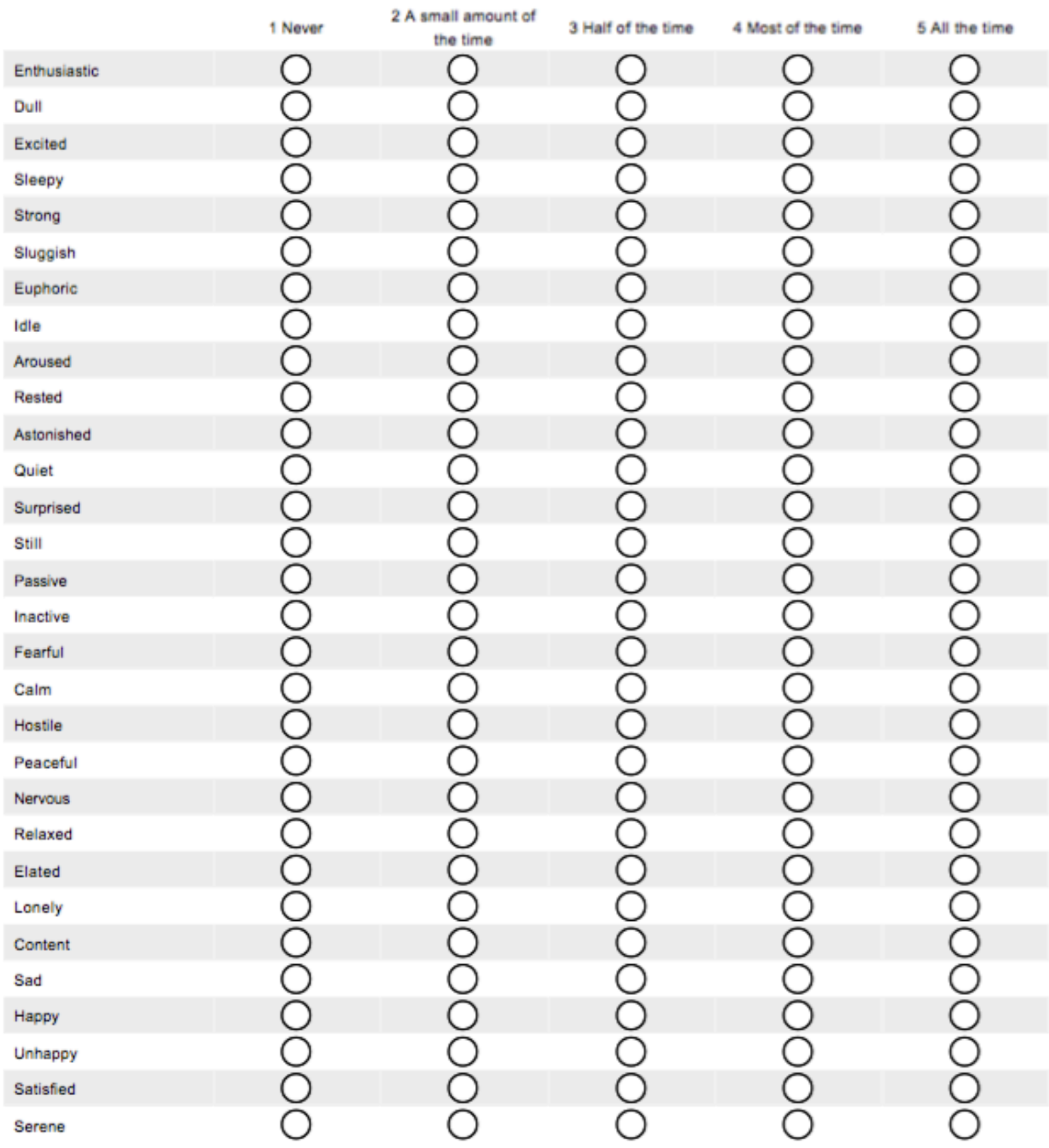


The Social Skills Improvement System (SSIS)

77. Please read each item and think about your child's behavior during the PAST TWO MONTHS. Then decide how often your child displays the behavior. Please mark every item. If you are uncertain of your response to an item, give your best estimate. There are no right or wrong answers.

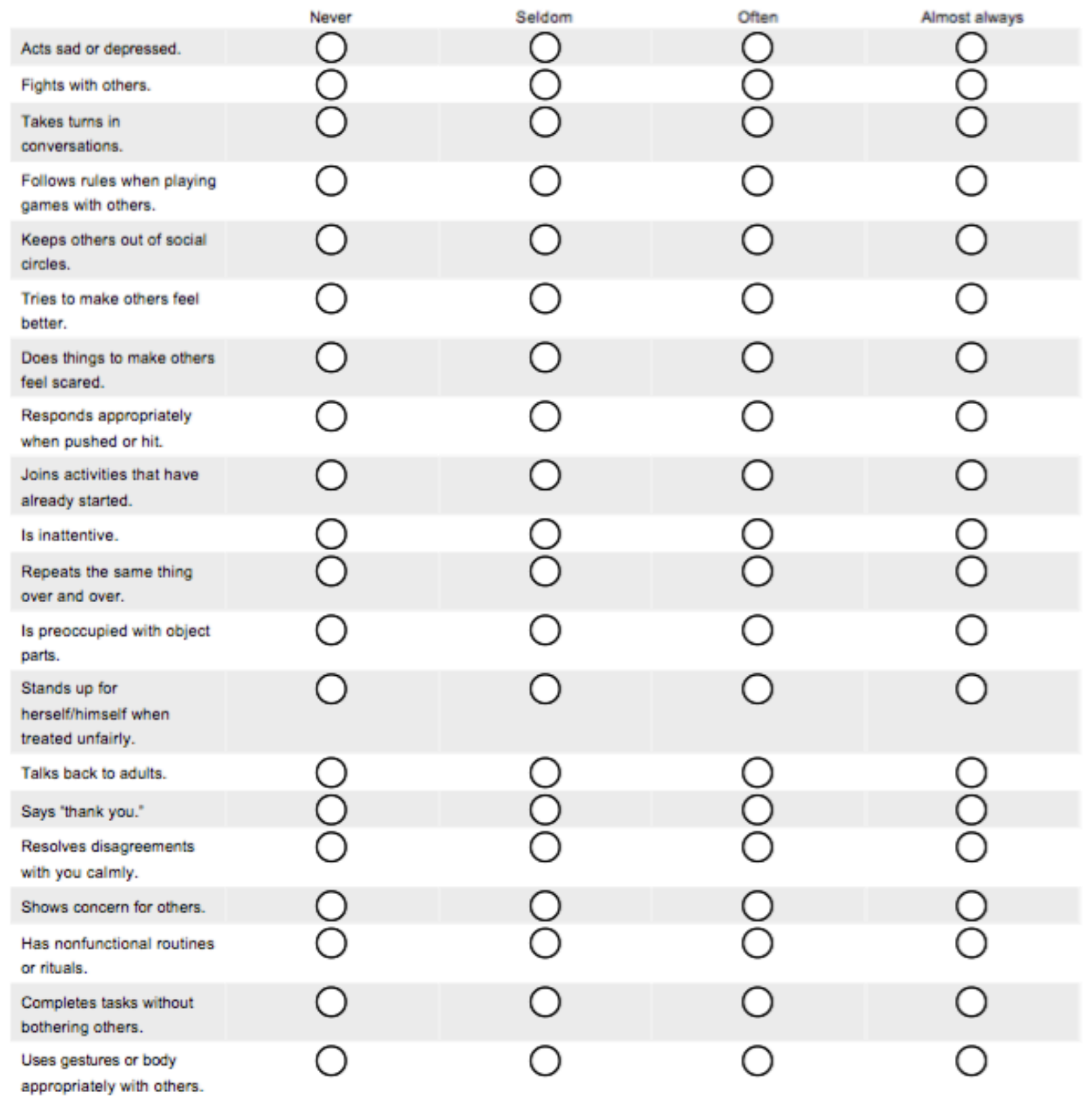

